\title{
LA ARMONIZACIÓN DE LAS PRÁCTICAS JURISPRUDENCIALES DEL TRIBUNAL EUROPEO DE DERECHOS HUMANOS Y DEL COMITÉ EUROPEO DE DERECHOS SOCIALES: UNA EVOLUCIÓN DISCRETA*
}

\author{
POR \\ GREGOR T. CHATTON \\ Departamento de Derecho constitucional de la Universidad \\ de Ginebra (Suiza). \\ Miembro de la "Red académica de la Carta Social Europea» \\ del Consejo de Europa.
}

\section{REFLEXIÓN PRELIMINAR: ¿¿DE QUÉ ARMONIZACIÓN HABLAMOS?}

Para la voz «armonización» (derivado del latín harmonia: arreglo), el Diccionario jurídico elaborado bajo la dirección de Gérard Cornu ofrece los tres sig-

* Traducción del original francés por Luis Jimena Quesada (Universitat de València). El presente trabajo, bajo el título original francés «L'harmonisation des pratiques jurisprudentielles de la Cour européenne des droits de l'homme et du Comité européen des droits sociaux: une évolution discrète», es la traducción de un artículo aparecido en la obra colectiva L'harmonisation internationale du droit [CHAPpUIS, Ch./FOËX, B./KADNER, Th. (édit.)], Éd. Schulthess, Genève, 2007, pág. 45 ss. 
nificados siguientes: «1. Operación legislativa que consiste en hacer compatibles disposiciones de origen ( $y$, a menudo, de fecha) diferente, y especialmente en modificar disposiciones existentes con el fin de hacerlas coherentes con una nueva reforma (vid. codificación, coordinación, modificación, orden). 2. Operación consistente en unificar conjuntos legislativos diferentes mediante la elaboración de un Derecho nuevo que se nutre de unos y otros textos (vid. unificación, unidad). 3. Designa a veces una simple aproximación entre dos o más sistemas jurídicos; por ejemplo, armonización de legislaciones europeas (vid. coordinación)» ${ }^{1}$.

Ciertamente, el Tribunal Europeo de Derechos Humanos (TEDH o Tribunal) ${ }^{2}$ y el Comité Europeo de Derechos Sociales (CEDS o Comité) ${ }^{3}$ representan dos órganos independientes el uno del otro. Aunque los dos posean sus vínculos institucionales en el seno de la Dirección de Derechos Humanos del Consejo de Europa $^{4}$, y aunque los tratados que los instituyen estén considerados como

${ }^{1}$ Cornu, Gérard (dir.): Vocabulaire juridique [Association Henri Capitaint (édit.)], 7e éd., Paris, 2005, pág. 423.

${ }^{2}$ Con el fin de garantizar el respeto de los compromisos que resultan para las Altas Partes Contratantes del Convenio y de su Protocolos Adicionales, el artículo 19 del Convenio para la salvaguardia de los derechos humanos y las libertades fundamentales de 4 de noviembre de de 1950 (CEDH) establece un Tribunal Permanente. Al margen de una competencia consultiva accesoria, el Tribunal Europeo de Derechos Humanos conoce tanto de demandas interestatales como individuales.

3 El Comité Europeo de Derechos Sociales — anteriormente denominado «Comité de expertos independientes» - constituye un órgano cuasijurisdicional instaurado por el artículo 25 de la Carta Social Europea de 18 de octubre de de 1961 (CSE) y reintegrado en la Carta Social Europea Revisada de 8 de mayo de de 1996 (CSER), convenio llamado a sustituir progresivamente al primer instrumento, así como a su Protocolo adicional de 5 de mayo de de 1998. En virtud del artículo 24 CSER, el Comité Europeo aprecia, desde un punto de vista jurídico y a través del examen de informes periódicos, la conformidad de las leyes, los reglamentos y las prácticas nacionales con el contenido de las obligaciones que derivan de la Carta. Bajo el ángulo del Protocolo adicional a la CSE que establece un sistema de reclamaciones colectivas de 9 de noviembre de de 1995, y por remisión del artículo D CSER, el Comité Europeo es igualmente competente para conocer las reclamaciones colectivas que formulen las organizaciones de empresarios y de trabajadores, así como algunas otras organizaciones especialmente cualificadas en los ámbitos cubiertos por la Carta.

${ }^{4}$ BRILlaT, Régis: «L'activité pré-conventionnelle et para-conventionnelle de Conseil de l'Europe dans le domaine des droits sociaux", in Droits sociaux et droit européen - Bilan et prospective de la protection normative (Actes de la journée d'études de 19 octubre de 2001) [FLAUSS, Jean-François (édit.)], Bruxelles, 2002, pág. 127 ss, 129; GrEVISSE, Suzanne: «Le renouveau de la Charte sociale européenne», Droit social, n. ${ }^{\circ}$ 9/10, Paris 2000, pág. 884 ss, 885; HARRIS, David, "A Fresh Impetus for the European Social Charter", International and Comparative Law Quarterly, n. 41, Londres 1992, pág. 659 ss, 660; HARRIS, David / DARCY, John, The European Social Charter, 2e éd., Ardsley, 2001, pág. 13. 
complementarios, incluso gemelos 5 , no por ello dejan de presentar regímenes jurídicos distintos.

La primera definición referente a una armonización legislativa lato sensu no es por tanto susceptible de ser aplicada. Pese a que la técnica de las alusiones mutuas forme parte — como vamos a estudiar — de los métodos utilizados, la segunda opción queda igualmente desprovista de virtualidad: tanto los motivos evocados más arriba como el hecho de que no parece codiciarse una unificación jurídica como tal, coadyuvan efectivamente a descartar la segunda definición propuesta. Resta, por ende, el tercer significado, el cual - menos formaltiende hacia la coordinación o hacia la aproximación entre dos o más sistemas jurídicos.

En nuestra opinión, la convergencia de las prácticas jurisprudenciales operada por el Tribunal y por el Comité se inserta precisamente en ese tercer registro léxico. Es a través de una multitud de aproximaciones discretas, tanto deseadas como inherentes al objeto del tratado, como ambos órganos con sede en Estrasburgo progresan hacia una armonización cada vez más pronunciada de sus enfoques respectivos.

\section{LOS DERECHOS CIVILES Y LOS DERECHOS SOCIALES FUNDAMENTALES: CONVERGENCIAS TEÓRICAS}

\section{La interdependencia}

«Todos los derechos humanos son universales, indisociables, interdependientes y están íntimamente relacionados. La comunidad internacional debe tratar los derechos humanos globalmente, de manera equitativa y equilibrada, en pie de igualdad y otorgándoles un valor igual». Así aparece formulado el credo

5 Cf. p. e.: BRILLAT, Régis: "The European Social Charter», in International human rights monitoring mechanisms - Essays in honour of Jakob Th. Möller [ALFREDSSON, Gudmundur I GrimHeden, Jonas / RaMcharan, Bertram G. / ZaYAS, Alfred De (édit.)], La Haye, Boston, Londres, 2001, pág. 601 ss, 601; Evju, Stein: «The European Social Charter», in The Council of Europe and the Social Challenges of the XXIst Century [BLANPAIN, Roger (édit.)], La haye, Londres, Boston, 2001, pág. 19 ss, 20; OBERLEITNER, Gerd: «Developing Social Rights in Europe Further: the revised European Social Charter and the Collective Complaints Protocol», in Development and developing International and European Law - Essays in honour of Konrad Ginther on the occasion of his 65th Birthday [BENEDEK, Wolfgang / IsAK, Hubert / KiCKER, Renate / LANG, Peter (édit.)], Francfort et al. 1999, pág. 637 ss, 642. 
tan frecuentemente citado de la Declaración final de Viena de $1993^{6}$. Tras haber sido ignoradas durante mucho tiempo esas bellas palabras y haberse considerado a los derechos humanos sociales como (no) derechos utópicos, demasiado vagos para ser justiciables, onerosos y contrarios al principio de la separación de poderes, la doctrina jurídica finalmente se ha rendido a la evidencia de que la plena realización de los derechos humanos pasa inevitablemente por la garantía simultánea de los derechos sociales y de que la mayor parte de las objeciones formuladas hasta ahora han sido manifiestamente erróneas o excesivamente exageradas $^{7}$. Si bien no procede, en el marco del presente estudio, detenerse a refutar detalladamente el conjunto de trivialidades que se han vertido sobre los derechos sociales, resulta no obstante interesante subrayar la complementariedad que existe entre derechos civiles y derechos sociales.

Intuitivamente, podemos preguntarnos en primer lugar para qué sirven el derecho al respeto de la vida privada, la libertad de pensamiento, la libertad de expresión o la libertad de reunión, si una persona sin educación ni perspectivas profesionales se encuentra sin un techo en el que cobijarse, se ve obligada a buscar comida permanentemente y no dispone, por consiguiente, de energía ni de voluntad suficientes para preocuparse por algo que no sea la propia satisfacción de sus necesidades elementales de subsistencia; o si su situación de miseria la coloca al margen de la sociedad y de sus semejantes ${ }^{8}$. Por otra parte, ¡‘cómo pueden

${ }^{6}$ Conferencia mundial sobre derechos humanos, Declaración y programa de acción de Viena de 26 de junio de de 2004 (ONU doc. A/CONF.157/23), $\$ 5$, en donde se lee: «sobre no poder perderse de vista la importancia de los particularismos nacionales y regionales y la diversidad histórica, cultural y religiosa, es deber de los Estados, cualquiera que sea su sistema político, económico y cultural, promover y proteger todos los derechos humanos y todas las libertades fundamentales».

7 Así, por ejemplo, (a) Los términos «derecho al trabajo» o «derecho a la salud» no son más que diminutivos de un derecho a que el Estado facilite el acceso a un trabajo decente o a que el individuo tenga acceso a los cuidados y tratamientos que le permitan alcanzar el estado de salud constitucionalmente posible. (b) Numerosos derechos civiles y políticos son formulados de manera tan vaga e indeterminada como los derechos sociales, con la sola diferencia prácticamente de que estos últimos han podido ser, durante décadas, concretados a través de la jurisprudencia nacional. La exégesis que se desprende del examen de los informes (Observaciones finales, Conclusiones) y de las Observaciones generales de los órganos de control internacionales ha permitido sin embargo atenuar esa criba durante los últimos quince años. (c) En cuanto al argumento referente al carácter oneroso de los derechos sociales, al principio de la separación de poderes y a la justiciabilidad, quedarán (implícitamente) refutados por nuestros desarrollos subsiguientes: véase, p.e., la obra colectiva BenoIT-RoHMER, Florence / GREWE, Constance (édit.): Les droits sociaux ou la démolition de quelques poncifs, Strasbourg 2003.

${ }^{8}$ Cf., Para el derecho a la salud: Hammond, Rachel / OOMS, Gorik: «World Bank policies and the obligation of its members to respect, protect and fulfil the right to health», in Health and Human Rights, n. ${ }^{\circ}$ 8/1, Boston 2004, pág. 27 ss, 28. 
garantizarse de modo duradero los derechos sociales si los individuos están privados de la información que les permita evaluar los efectos concretos generados por las políticas económicas, o si las garantías procedimentales, sus derechos de participación política, son vulnerados??

Dogmáticamente, la imagen tradicional de los derechos civiles, que se sustenta en el concepto revolucionario de propiedad (1789), es una imagen de barreras contra la intervención del Estado, el cual se presenta a mayor abundamiento como obligado a respetar la igualdad jurídica de todos y cada uno sin perjuicio de su situación de hecho. Con un tono sarcástico, Anatole France ha evocado, a este respecto, la idea de una igualdad de fachada, de una ley que, "con una gran preocupación por la igualdad, prohíbe tanto a los ricos como a los pobres dormir bajo un puente, mendigar en la calle y robar pan ${ }^{10}$. Los derechos sociales saltarán a la escena interesándose por el «hombre ubicado en la sociedad», a saber, por el ser humano de carne y hueso. Los derechos sociales revisten así la igualdad y la libertad formales de una aceptación material o sustancial, buscando crear las condiciones indispensables para el disfrute de las primeras y dotar de autonomía a las personas vulnerables que de otro modo no tendrían esa posibilidad ${ }^{11}$. Ahora

9 Beetham, David: «What Future for economic and social rights?», in Political Studies, vol. 43, n. ${ }^{\circ}$ especial, Oxford, Cambridge, 1995, pág. 41 ss, 49.

${ }^{10}$ Cita tomada de Anatole FrANCE: Le lys rouge (1894), que Matscher FrANZ: «Naturrecht, menschenrechte, völkerrecht», in Völkerrechtsordnung und Völkerrechtsethik [WEILER, Rudolf (édit.)], Berlin 2000, pág. 97 ss, 98, presta al escéptivo Ernest RENAN. Veáse también BEDJAOUI, Mohammed: "La difficile avancée des droits de l'homme vers l'universalité, in Universalité des droits de l'homme dans un monde pluraliste - Actes de colloque (Strasbourg, 17-19 abril de 1989) [Conseil de l'europe (édit.)], Strasbourg,1990, pág. 35 ss, 37; GARCía RAMírEZ, Sergio: «Raíz y horizonte de los derechos «sociales» en la Constitución mexicana», in Liber amicorum Héctor FixZamunda [Corte interamericana de derechos humanos (ed.)], vol. I, San José, 1998, pág. 77 ss, 82; HeNKIN, Louis: "Economic-social rights as 'rights'. A united states perspective», in Human Rights Law Journal, n. ${ }^{\circ}$ 2/3-4, Kehl, Strasbourg, Arlington, 1981, pág. 223 ss, 229; KATROUGALOS, George S.: «Human Rights in the Welfare State», in Jahrbuch des öffentlichen Rechts der Gegenwart [HÄBERLE, Peter: (édit.)], vol. 44, Tubingue, 1996, pág. 137 ss, 147; NEUnER, Jörg: «Los derechos humanos sociales», in Anuario Iberoamericano de Justicia Constitucional, n. ${ }^{\circ}$ 9, madrid 2005, pág. 239 ss, 247; Woods, Jeanne M.: "Justiciable Social Rights as a Critique of the Liberal Paradigm", in Texas International Law Journal, n. ${ }^{\circ}$ 38, Austin 2003, pág. 763 ss, 770.

${ }_{11}$ DonNeluY, Jack: International Human Rights, 2. ${ }^{a}$ ed., Boulder, oxford 1998, pág. 23; NeUNER (n. 10), pág. 245 s.: «Los derechos humanos sociales son una condición básica para el ejercicio y la garantía de la libertad individual, puesto que la libertad jurídica amenaza con quedar vacía si faltan los presupuestos fácticos»; PeCES-BARbA MARTíneZ, Gregorio: "Reflections on economic, social and cultural rights", in Human Rights Law Journal, n. ${ }^{\circ}$ 2/3-4, Kehl, Strasbourg, Arlington, 1981, pág. 281 ss, 292; YeLTEKIN, Niyazi: La nature juridique des droits de l'homme, Thèse, Lausanne, 1950, pág. 55 \& 60. 
bien, el progreso que han conocido tanto el Derecho internacional de los derechos humanos como los derechos fundamentales, en particular en la Europa de la posguerra, ha llegado a borrar sensiblemente las fronteras que existían entre esas dos funciones.

\section{Las obligaciones estratificadas}

Como reacción a las numerosas críticas formuladas frente a los derechos económicos, sociales y culturales, y sobre todo en el tiempo de la Guerra Fría, algunos tenores de la doctrina de la justiciabilidad de los derechos sociales, tales como Shue, Van Dijk, Alston, Eide, Waldron o Sepúlveda, han elaborado una verdadera teoría de los derechos sociales con el fin de desarrollar la comprensión de estos derechos de "segundo rango» ${ }^{12}$, que se ha convertido casi unánime poco a poco ${ }^{13}$ y sistemáticamente aplicada por el Comité de la ONU que vela por la aplicación del Pacto internacional de derechos económicos, sociales y culturales ${ }^{14}$, dicha doctrina examina los derechos sociales bajo el ángulo de las obligaciones que los mismos generan ${ }^{15}$ : esa doctrina ha venido a extenderse paulatinamente a todos los derechos fundamentales. Si como indica Koch, los derechos humanos engendran en realidad un "continuum» de obligaciones, la teoría de los tres estratos adoptada por la doctrina se revela bastante útil a fines didácticos ${ }^{16}$.

El primer nivel de obligaciones encomienda al Estado que respete el derecho fundamental en cuestión, es decir, que se abstenga de obstaculizar su libre ejer-

12 Una presentación de las diversas teorías se contiene en la obra de SEPÚLVEDA, Magdalena: The nature of the obligations under the international Covenant on economic, social and cultural rights, Anvers, Oxford, New York 2003, cap. v. Ver también: KoCH, Ida Elisabeth: «Dichotomies, trichotomies or waves of duties?», in Human Rights Law Review, n. ${ }^{\circ}$ 5/1, Oxford 2005, pág. 81 ss, 84 ss. Cf. igualmente: The Limburg Principles on the Implementation of the International Covenant on economic, social and cultural rights", in Human Rights Quarterly, n. ${ }^{\circ}$ 9/2, Baltimore 1987, $122-135 \&$ in (ONU doc. E/CN.4/1987/17, Ann.).

13 ... Si se hace caso omiso de los debates interminables sobre el número exacto de estratos o categorías o la incorporación de tal o cual elemento a los diferentes estratos. En el marco de la presente contibución, nos basaremos en elm odelo utilizado por el Comité del Pacto de derechos económicos, sociales y culturales.

${ }^{14}$ Pacto internacioal de 16 de diciembre de de 1966 de derechos económicos, sociales y culturales (RS 0.103.1).

15 Cf., para un acercamiento a todo ese desarrollo: SePÚlVEdA (n. 12), pág. 196 ss. Ver también: KÄLIN Walter / KÜNZLI, Jörg: Universeller Menschenrechtsschutz, Bâle, Genève, Munich, 2005, pág. 100 ss.

$1616 \mathrm{KoCH}$ (n. 12), pág. 103. 
cicio. Así, el derecho a la educación requiere que todo individuo tenga en principio libre acceso a una escuela, sin que el Estado se inmiscuya indebidamente imponiendo barreras legislativas, administrativas o otros obstáculos desproporcionados. El segundo nivel consiste en proteger los derechos fundamentales y obliga a los Estados a velar por que cualquier individuo no entorpezca el ejercicio de los derechos fundamentales por otro. Así, la realización del derecho a la vivienda requiere no solamente que el Legislador nacional introduzca normas protectoras relativas a los derechos del inquilino y del propietario, sino también que el Estado vele por su aplicación efectiva. Algunos derechos pueden, por añadidura, generar obligaciones más específicas, tales como actos materiales de protección por parte de los poderes públicos. El tercer estrato obliga al Estado, finalmente, a poner en práctica los derechos fundamentales de manera apropiada. Para ello, el Estado gozará de un amplio margen de apreciación. Deberá, en particular, emplearse en la organización de campañas de sensibilización y de formación (por ejemplo, para el consumo de agua potable), desarrollar programas y estrategias, así como adoptar todo tipo de medidas administrativas, legislativas o promocionales que puedan favorecer la protección efectiva de los derechos humanos. Ya parece un clásico que medidas de orden (infra-)estructural formen parte de este estrato. Sobre tratarse a menudo de medidas onerosas en términos monetarios y en recursos humanos (necesidad de coordinación, esfuerzos de planificación), algunos aspectos de este estrato de obligatoriedad sólo se realizan plenamente con el paso del tiempo. Como ejemplo concreto, podrían citarse las medidas de control y de fomento que son a veces necesarias para mantener la diversidad en los medios de comunicación, emanación de la libertad civil de expresión ${ }^{17}$. Únicamente estos aspectos progresivos podrán, en su caso, plantear problemas desde la perspectiva de la justiciabilidad. Por tanto, será la causa concreta que conozca un tribunal la que determine las competencias de este último y la aplicabilidad directa de una norma en un caso particular. No será pues el encuadre de un derecho humano u otro en tal o cual clasificación ${ }^{18}$.

${ }_{17}$ Aliprantis, Nikitas: Les droits sociaux sont justiciables!, in Droit social, n. ${ }^{\circ}$ 2, Paris 2006, pág. $158 \mathrm{ss}, 160 \mathrm{~s}$.

${ }^{18}$ HUNT, Paul: Reclaiming social rights - Iinternational and Comparative perspectives, Aldershot, Brookfield, Singapour, Sydney 1996, pág. 34; KоCH, Ida Elisabeth: «The justiciability of indivisible Rights», in Nordic journal of international Law, n. ${ }^{\circ}$ 72, La haye, Boston, Londres 2003, pág. 3 ss, 21. Sin embargo, incluso el tercer nivel obligacional no se sustrae necesaria y completamente al control judicial. Junto a la verificación del modo en que el Estado otorga prestaciones mínimas a los más vulnerables (derecho al mínimo existencial), la realización de las medidas progresivas del tercer estrato puede ser verificada por el juez bajo el ángulo del carácter razonable de la naturaleza de los medios empleados y del ritmo de los progresos efectuados. Cf. p.e, Tribunal 


\section{EL TRIBUNAL Y EL COMITÉ: CONVERGENCIAS PRÁCTICAS}

\section{1. ¿Una simetría de carácter obligatorio?}

Si la teoría de los estratos ha visto la luz en el plano universal y se entiende en tanto que contrapeso a algunas veleidades nacionales y doctrinales tendentes a privar al Pacto de derechos económicos, sociales y culturales de cualquier relevancia jurídica —ello, por ejemplo, a través de una interpretación reductora de su cláusula de realización progresiva ${ }^{19}$ - , no es menos cierto que esa teoría ha venido a aplicarse igualmente en el sistema de protección europeo, que sin embargo ha plebiscitado otras terminologías. Ahora bien, a medida que se van desarrollando las jurisprudencias del Tribunal y del Comité, es evidente que tanto el Convenio Europeo como la Carta Social revisada contienen obligaciones de respeto, de protección y de puesta en práctica ${ }^{20}$.

\subsection{Las obligaciones de respeto}

Tradicionalmente, los derechos civiles y políticos son percibidos como «derechos-libertades» que requieren una actitud de abstención por parte del Estado. En la medida en que la mayor parte de las garantías contenidas en el Convenio Europeo se inscriben precisamente en esas dos categorías, no debe extrañar tanto que la jurisprudencia del Tribunal Europeo aborde violaciones alegadas que resulten de injerencias injustificadas por parte de las autoridades públi$\mathrm{cas}^{21}$. En sentido contrario, uno de los estereotipos que circulan a propósito de los derechos sociales tiene que ver con su carácter intrínsicamente oneroso, del que por lo demás se derivaría su ausencia de justiciabilidad. Ahora bien, la jurisprudencia elaborada por el Comité Europeo de Derecho Sociales en el marco del mecanismo de las reclamaciones colectivas demuestra lo vano que resulta dicho argumento. En la reclamación colectiva n. ${ }^{\circ}$ 7/2000 contra Grecia, la Fede-

Constitucional de Sudáfrica, Minister of Health \& Others v Treatment Action Campaign (TAC) \& Others (n. ${ }^{\circ}$ 2), de 5 de julio de de 2002, CCt 8/02, 2002 (5) sa 721 (CC), $\$ 22$.

19 Cf. art. $2 \$ 1$ del Pacto de derechos económicos, sociales y culturales.

${ }^{20}$ Cf., p. e.: KäLIN / KÜNZLI (n. 15), pág. 100 ss.

${ }^{21}$ Los ejemplos son numerosísimos, por lo que bastará con citar las jurisprudencias siguientes: SsTEDH, Jalloh c. Alemania (Gran Sala), de 11 julio de 2006, demanda 54810/00; Cumpana y Mazare c. Rumania (Gran Sala), de 17 diciembre de 2004, demanda 33348/96, rec. 2004-XI; Sahin c. Alemania (Gran Sala), de 8 julio de 2003, demanda 30943/96, rec. 2003-VIII; Hassan y Tchaouch c. Bulgaria (Gran Sala), de 26 octubre de 2000, demanda 30985/96, rec. 2000-XI. 
ración internacional de ligas de derechos humanos hacía valer entre otros argumentos que un decreto legislativo griego de 1973, que permanecía en vigor a pesar de once años de constantes críticas, violaba el artículo 1.2 de la Carta ${ }^{22}$ en la medida en que prohibía a los militares de carrera que habían disfrutado de varios períodos de formación el abandonar el ejército antes de que pasaran veinticinco años de servicio. Al enfocar el artículo 1.2 de la Carta Social bajo el ángulo de la prohibición del trabajo forzado u obligatorio, el Comité estimó la reclamación e instó a Grecia a que, inmediatamente, remediara la situación de conformidad con la Carta Social ${ }^{23}$.

De manera aún más interesante, la reclamación n. ${ }^{\circ}$ 8/2000 contra Grecia permitió al Comité Europeo dotar al artículo 1.2 de la Carta de una muy novedosa faceta protectora de la libertad de trabajar. En la medida en que el servicio social sustitutorio del servicio militar obligatorio escapa al ámbito de aplicación de la prohibición del trabajo forzado a tenor de lo que prevé el artículo 4.2.b) del Convenio Europeo, el Comité examinó el impacto de la duración del servicio civil sobre la incorporación de los jóvenes objetores de conciencia griegos al mercado laboral. Teniendo en cuenta que la duración del servicio civil era superior en más de dieciocho meses a la duración del servicio militar y que esa duración superior podía llegar incluso a los treinta y nueve meses (sic), el Comité constató que «las modalidades y condiciones de ejercicio del servicio civil sustitutorio constituyen (...) una restricción desproporcionada a la libertad» de ganarse la vida mediante un trabajo libremente elegido ${ }^{24}$.

En cuanto a la reclamación colectiva n. ${ }^{\circ} 14 / 2003$, la misma condujo al Comité a analizar la conformidad de una reforma legislativa francesa referente al derecho a la salud de los «sin papeles» y de sus hijos ${ }^{25}$. En el caso de autos, dicha reforma había restringido el derecho a las prestaciones médicas de esa categoría vulnerable de personas a aquellas situaciones que ponían en juego el pronóstico inmediato durante los tres primeros meses de residencia, lo que el Comité declaró incompatible con la Carta en lo que afectaba a la «subcategoría» todavía

${ }^{22}$ Art. $1 \$ 2$ CSE: «Para garantizar el ejercicio efectivo del derecho al trabajo, las Partes se comprometen: (...) a proteger de manera eficaz el derecho del trabajador a ganarse la vida mediante un trabajo libremente elegido». La cursiva es nuestra.

23 DCEDS (en adelante, Decisión del Comité Europeo de Derechos Sociales) Federación internacional de ligas de derechos humanos (FIDH) c. Grecia, de 5 diciembre de 2000, reclamación n. ${ }^{\circ} 7 / 2000$ (fondo), $\$ 21 \& 23$.

24 DCEDS Consejo cuáquero para asuntos europeos (QCEA) c. Grecia, de 25 abril de 2001, reclamación n. ${ }^{\circ} 8 / 2000$ (fondo), $\$ 22-25$.

25 Art. 13 y 17 (para los niños) CSER. 
más frágil de niños «sin papeles» ${ }^{26}$. En fin, en otro asunto, el Comité Europeo juzgó que la práctica sistemática de la policía italiana consistente en expulsar en cualquier período - o en amenazar de expulsar a las personas itinerantes de sus lugares de estacionamiento, así como en la destrucción de los bienes de su pertenencia y en la injerencia en sus viviendas móviles, constituía una violación discriminatoria de su derecho a la vivienda (artículo 31 de la Carta Social revisada) ${ }^{27}$.

\subsection{Las obligaciones de protección}

\section{A) En el ámbito del Convenio Europeo de Derechos Humanos (CEDH)}

Desde sus emblemáticas sentencias dictadas en el asunto lingüistico belga $\mathrm{y}$, más tarde, en el asunto Markx ${ }^{28}$, el Tribunal Europeo no ha cesado - a favor de la efectividad de las garantías del $\mathrm{CEDH}^{29}$ - de desarrollar la noción pretoriana de las «obligaciones positivas». En la actualidad, no existe prácticamente disposición convencional alguna que no haya hecho pesar todavía sobre los Estados obligaciones de intervención positiva ${ }^{30}$. Ahora bien, la mayor parte de las situa-

${ }^{26}$ DCEDS Federación internacional de ligas de derechos humanos (FIDH) c. Francia, de 8 septiembre de 2004, reclamación n. ${ }^{\circ}$ 14/2003 (fondo), $\$ 36$ s.

27 DCEDS Centro de Derechos para los Gitanos Europeos (CEDR) c. Italia, de 7 diciembre de 2005, reclamación n. ${ }^{\circ}$ 27/2004 (fondo), $\$ 41$ s.

${ }^{28}$ STEDH Asunto relativo a algunos aspectos del régimen lingüístico de la enseñanza en Bélgica c. Bélgica (principal), de 23 julio de 1968, demandas 1474/62; 1677/62; 1691/62; 1769/63; 1994/63; 2126/64, série A6, \$7; Marckx c. Bélgica, de 13 junio de 1979, demanda 6833/74, série $\mathrm{A} 31, \$ 31$.

29 Según Mowbray, Alastair: The development of positive obligations under the European Convention on Human Rights by the European Court of Human Rights, Oxford, Portland, 2004, pág. 5, las obligaciones positivas contarían con una triple justificación teórica: «First, the requirement under article 1 that states should secure Convention rights to all persons within their jurisdiction. Secondly, the principle that Convention rights must be practical and effective. Thirdly, the principle, derived from article 13, that effective domestic remedies should be provided for arguable breaches of Convention rights».

30 Ver, entre otras muchas: SsTEDH, L.C.B. c. Reino Unido, de 9 junio de 1998, demanda 23413/94, rec. 1998-iii, $\$ 36$ (art. 2 CEDH); Ilhan c. Turquía (Gran Sala), de 27 junio de 2000, demanda 22277/93, rec. 2000-vii, \$86 s; A. c. Reino Unido, de 23 septiembre de 1998, demanda 25599/94, rec. 1998-vi, \$22 (art. 3 CEDH); Siliadin c. Francia, de 26 julio de 2005, demanda 73316/01, $\$ 148$ s. (art. $4 \mathrm{CEDH}$ ); Kurt c. Turquía, de 25 mayo de 1998, demanda 24276/94, rec. 1998-iii, \$128 s.; Kalachnikov c. Rusia, de 15 julio de 2002, demanda 47095/99, rec. 2002-vi, \$ 114 (art. 5 CEDH); Guincho c. Portugal, de 10 julio de 1984, demanda 8990/80, 
ciones en las que el Tribunal forja semejantes obligaciones a partir de garantías materiales — aisladamente o en combinación con el artículo $1 \mathrm{CEDH}$ - conciernen a atentados o restricciones que emanan de terceros, de tal manera que la noción "clásica» de obligaciones positivas viene a equipararse sin dificultad a las obligaciones de protección del ya mencionado segundo estrato de derechos.

Por efecto de una jurisprudencia evolutiva y teleológica del Tribunal Europeo $^{31}$, las obligaciones positivas se han ido diversificando poco a poco para tener en cuenta diferentes circunstancias y maneras a través de las cuales el Estado puede y debe proteger a los individuos contra los ataques que procedan de terceros. Primeramente, el marco legislativo de un Estado debe ofrecer una protección suficiente y adecuada a las personas que se encuentren bajo su jurisdicción, ya se trate en el plano de los recursos frente a una violación ya producida, ya se trate en el ámbito de los efectos disuasivos desplegados con carácter previo. En el asunto $A$, el Tribunal reprochó así al Reino Unido el no haberse dotado de una ley que de manera suficiente situara a los niños «al abrigo de todo trato o pena contrarios al artículo 3». En efecto, el common law inglés admitía los castigos corporales de «carácter razonable», lo que permitió a un tribunal nacional absolver al padrastro del demandante, que le había golpeado regularmente con un

série A81, $\$ 38$ (art. 6 CEDH); Mikulic c. Croacia, de 7 febrero de 2002, demanda 53176/99, rec. 2002-i, $\$ 64$ (art. $8 \mathrm{CEDH);} \mathrm{Otto-Preminger-Institut} \mathrm{c.} \mathrm{Austria,} \mathrm{de} 20$ septiembre de 1994, demanda 13470/87, série A295-a, $\$ 47$ (art. 9 CEDH); Özgür Gündem c. Turquía, de 16 marzo de 2000, demanda 23144/93, rec. 2000-iii, $\$ 71$ (art. 10 CEDH); Plattform «Ärzte für das Leben» c. Austria, de 21 junio de 1988, demanda 10126/82, série A139, $\$ 50$ (art. $11 \mathrm{CEDH}$ ); Kudla c. Polonia (Gran Sala), de 26 octubre de 2000, demanda 30210/96, rec. 2000-xi, $₫ 155$ ss; Ergi c. Turquía, de 28 julio de 1998, demanda 23818/94, rec. 1998-iv, $\$ 98$ (art. 13 CEDH); Natchova y otros c. Bulgaria (Gran Sala), de 6 julio de 2005, demanda 43577/98; 43579/98, \$ 160 (art. 14 CEDH); Öneryildiz c. Turquía (Gran Sala), de 30 noviembre de 2004, demanda 48939/99, rec. 2004-xii, $\$ 134$ (art. 1 Prot. n. ${ }^{\circ} 1$ al CEDH); Mathieu-Mohin y Clerfayt c. Bélgica, de 2 marzo de 1987, demanda 9267/81, série A113, $\$ 50$ (art. 3 Prot. n. ${ }^{\circ} 1$ al CEDH). Cf. asimismo: AKANDJI-KOMBÉ, Jean-François: Les obligations positives en vertu de la Convention européenne des droits de l'homme - Un guide pour la mise en oeuvre de la Convention européenne des droits de l'homme, Précis sur les droits de l'homme n. ${ }^{\circ}$ 7, Strasbourg 2006, pág. 6; BESSON, Samantha: «Les obligations positives de protection des droits fondamentaux - Un essai en dogmatique comparative», in Revue de droit suisse, n. ${ }^{\circ}$ 122/I, Bâle 2003, pág. 49 ss, 75; KoCH (n. 12), pág. 98; SUDRE, Frédéric: «Esclavage domestique et Convention européenne des droits de l'homme - À propos de l'arrêt siliadin c/ Francia», in Bulletin d'information sur les droits de l'homme, n. ${ }^{\circ}$ 66, Strasbourg 2005, pág. 23 ss, 25.

31 STEDH Annoni di Gussola y Debordes y Omer c. Francia, de 14 noviembre de 2000, demanda 31819/96; 33293/96, rec. 2000-xi, $\$ 56$; Wemhoff c. Alemania, de 27 junio de 1968, demanda 2122/64, série A7, $\$ 8$. 
bastón $^{32}$. Igualmente, los Países Bajos fueron condenados por cuanto una laguna del Código Penal había impedido a una discapacitada mental, así como a su padre en nombre de la hija, que formularan una querella criminal contra el presunto culpable de la violación sufrida en un domicilio privado ${ }^{33}$.

En segundo lugar, las obligaciones positivas generan obligaciones procedimentales: por ejemplo, el Tribunal Europeo estima frecuentemente que hay violación de una garantía del CEDH por el hecho de que las autoridades de un Estado no hayan llevado a cabo una investigación efectiva con motivo de un homicidio, de un caso de tortura o de la desaparición forzada de una persona, e incluso con ocasión de unas pesquisas policiales ilegales ${ }^{34}$.

En tercer término, pueden ser impuestas a los Estados obligaciones de información o de asistencia cuando, en particular, las inmisiones creadas por una industria vecina son susceptibles de atentar contra la integridad, la vida privada o el derecho al respeto del domicilio ${ }^{35}$.

En cuarto lugar, sobre el Estado pesa una obligación administrativa de instruir y de formar a su personal, lo que es particularmente importante en el seno de la policía con respecto al uso de la fuerza ${ }^{36}$.

En quinto lugar, un Estado puede ser, según los casos, conminado a desplegar acciones materiales tendentes a prevenir violaciones del Convenio. Esto es especialmente cierto en instituciones penitenciarias, en el seno de las cuales se imponen una vigilancia y una organización diligentes para impedir actos de agresión de otros detenidos, o de los funcionarios de esas prisiones. Más allá de los muros de la prisión, las autoridades de policía podrían no obstante ser requeridas para proteger la vida o la integridad de los individuos, e incluso la existencia de una sociedad editora o el desarrollo pacífico de una manifestación. En tales casos, el Tribunal Europeo admitirá la violación de una obligación positiva de adoptar medidas de prevención concretas cuando «las autoridades conocerían o habrían debido conocer el momento en el que un individuo determinado habría sido amenazado de manera real e inmediata en su vida por actos crimi-

32 STEDH A. c. Reino Unido (n. 30), $\$ 24$.

33 STEDH X. e Y. c. Países Bajos, de 26 marzo de 1985, demanda 8978/80, série A91, $\$ 30$.

34 Ver, p.e.: STEDH H.M. c. Turquía, de 8 agosto de 2006, demanda 34494/97, \$30; Ogur c. Turquía (Gran Sala), de 20 mayo de 1999, demanda 21954/93, rec. 1999-iii, \$ 88 ss; Kaya c. Turquía, de 19 febrero de 1998, demanda 22729/93, rec. 1998-i, $\$ 86$.

35 Cf. STEDH Guerra y otros c. Italia (Gran Sala), de 19 febrero de 1998, demanda 14969/89, rec. 1998 -i, $\$ 60$.

36 STEDH Makaratzis c. Grecia (Gran Sala), de 20 diciembre de 2004, demanda 50385/99, rec. 2004-xi, $\$ 70$. 
nales de un tercero y no habrían adoptado, en el marco de sus competencias, las medidas que desde un punto de vista razonable podrían haber sido consideradas como aptas para paliar dicho riesgo ${ }^{37}, \mathrm{o}$ - de manera general— cuando, en la evaluación del establecimiento de un «justo equilibrio entre el interés general y los intereses del individuo», la balanza se inclina a favor de la protección del individuo ${ }^{38}$.

B) En el ámbito de la Carta Social Europea revisada (CSER)

Vigente desde el 1 de julio de de 1998, el procedimiento de reclamaciones colectivas naturalmente no ha dado lugar todavía a una jurisprudencia tan sólida como el marco del Convenio Europeo de Derechos Humanos. Además, el carácter de actio popularis de este procedimiento constriñe al Comité Europeo de Derechos Sociales a concentrarse en la conformidad de situaciones legales o prácticas con la Carta, lo cual sólo da pie para que en raras ocasiones pueda centrarse en la existencia de obligaciones positivas «tradicionales», asociadas a demandas individuales ${ }^{39}$.

Ello no obstante, es posible identificar algunas obligaciones de protección en el seno de la jurisprudencia sobre las reclamaciones: así, por ejemplo, el Comité ha precisado que la privatización de algunas actividades del Estado o que la delegación de competencias públicas en un tercero no pueden conducir a exonerar a aquél de su papel de garante de los derechos humanos contenidos en la Carta. En semejante constelación, la ausencia de un Estado regulador suficientemente atento podría en efecto animar a prestadores poco escrupulosos a establecer discriminaciones entre particulares, a privar a éstos del acceso a

37 STEDH Paul y Audrey Edwards c. Reino Unido, de 14 marzo de 2002, demanda 46477/99, rec. 2002-ii, $\$ 54$ s., en donde se precisa: «sin perder de vista las dificultades que tienen la policía al ejerer sus funciones en las sociedades contemporáneas, ni la imprevisibilidad del comportamiento humano ni las opciones políticas a operar en términos de prioridades y de recursos, debe interpretarse esta obligación de manera que no se imponga a las autoridades un carga insoportable o excesiva. Por consiguiente, cualquier presunta amenaza contra la vida no obliga a las autoridades, a la vista del Convenio, a adoptar medidas contretas para prevenir frente a semejante amenaza»; Özgür Gündem (n. 30), \$ 43; Osman c. Reino Unido (Gran Sala), de 28 octubre de 1998, demanda 23254/94, rec. 1998-viii, \$115 ss; Plattform «Ärzte für das Leben» (n. 30), \$ 32.

38 STEDH Özgür Gündem (n. 30), $\$ 43$.

39 Cf. la decisión de inadmisibilidad pronunciada respecto a una reclamación de tipo individual: DCEDS Sindicato de altos funcionarios (SAIGI) c. Francia, de 14 junio de 2005, reclamación n..$^{\circ}$ 29/2005 (admisibilidad), $\$ 8$. 
bienes o servicios esenciales o, más generalmente, a poner en peligro sus derechos fundamentales ${ }^{40}$.

Del mismo modo, el artículo 17 CESR, que protege a los niños y a los adolescentes, obliga a los Estados a «asegurar que la prohibición de toda forma de violencia tenga una base» específica en la ley nacional y a velar, en particular a través de sanciones «suficientes, disuasivas y proporcionadas", que dichas disposiciones sean realmente puestas en práctica ${ }^{41}$. Irlanda, sobre conocer la excepción consuetudinaria del "castigo razonable» puesta de manifiesto frente al Reino Unido en el asunto $A$ llevado ante el Tribunal Europeo, fue puesta en entredicho asimismo por el Comité Europeo de Derechos Sociales, quien consideró que la protección ofrecida por dicho país contra los castigos corporales en familias de acogida y en estructuras de guarda de niños no era suficiente ${ }^{42}$. En la reclamación n. ${ }^{\circ}$ 25/2004, el Comité Europeo interpretó el artículo 6.2 CSER con relación al derecho a la negociación colectiva en el sentido de obligar a los Estados a «adoptar medidas positivas para incentivar la consulta entre los sindicatos y las organizaciones empresariales», obligación que puede, en caso de inercia de los interlocutores sociales, requerir el establecimiento por el Estado de «estructuras y mecanismos permanentes» con representación paritaria ${ }^{43}$.

Si bien el Comité Europeo de Derechos Sociales no estimó que había violación en el caso de autos, de la reclamación n. ${ }^{\circ}$ 26/2004 se desprende que el artículo 5 CSER referente al derecho de sindicación posee una vertiente procedimental a tenor de la cual los sindicatos deben disponer de recursos eficaces para, por ejemplo, contestar la regularidad de elecciones en el seno de asambleas representativas ${ }^{44}$.

40 DCEDS Fundación Marangopoulos para los derechos humanos (FMDH) c. Francia, de 10 octubre de 2005 , reclamación $n$. $^{\circ} 30 / 2005$ (admisibilidad), $\$ 14$, relativa a una explotación de lignito semiprivatizada que presentaba riesgos para la salud y el medio ambiente.

${ }^{41}$ DCEDS Organización mundial contra la tortura $(\mathrm{OMCT})$ c. Irlanda, de 7 diciembre de 2004, reclamación n. ${ }^{\circ}$ 18/2003 (fondo), $\$ 64$.

${ }^{42}$ DCEDS OMCT c. Irlanda (n. 41), $\$ 65$ s. Recuérdese también: STEDH A. c. Reino Unido (n. 30), $\$ 24$. Cf. asimismo los asuntos: DCEDS Organización mundial contra la tortura (OMCT) c. Grecia, de 7 diciembre de 2004, reclamación n. ${ }^{\circ}$ 17/2003 (fondo), \$34-46; OMCT c. Italia, de 7 de diciembre de 2004, reclamación n. ${ }^{\circ}$ 19/2003 (fondo), $\$ 49$; OMCT c. Portugal, de 7 de diciembre de 2004, reclamación n. ${ }^{\circ}$ 20/2003 (fondo), $\$ 42$; OMCT c. Bélgica, de 7 de diciembre de 2004, reclamación n. ${ }^{\circ} 21 / 2003$ (fondo), $\$ 48$.

43 DCEDS Central general de los servicios públicos (CGSP) c. Bélgica, de 9 mayo de 2005 , reclamación n. ${ }^{\circ}$ 25/2004 (fondo), $\$ 41$.

${ }^{44}$ DCEDS Sindicato de profesores agregados de la enseñanza superior (SAGES) c. Francia, de 15 junio de 2005, reclamación n. ${ }^{\circ}$ 26/2004 (fondo), \$36-39. 
Por último, la inserción en los convenios colectivos laborales de cláusulas de monopolio o seguridad sindical previas a la contratación que sean «claramente contrarias a la libertad [sindical negativa implícitamente] garantizada por el artículo 5» de la Carta, impone a «las autoridades nacionales competentes - ya se trate de las instancias legislativas, reglamentarias o judiciales- que intervengan para anularlas o para prohibir su aplicación». Y ello pese a que en el Estado controvertido se haya confiado tradicionalmente la regulación del mercado laboral sólo a los interlocutores sociales ${ }^{45}$.

\subsection{Las obligaciones de puesta en práctica}

\section{A) En el ámbito de la CSER}

Si las más fervientes críticos de los derechos sociales no se sorprenderán lo más mínimo de ver cómo las garantías de la Carta Social (revisada) encierran obligaciones onerosas y estructurales, realizables en el tiempo, quedarán probablemente desconcertados de ver cómo esas obligaciones han devenido justiciables. Ciertamente, podrá argüirse, se trata de una justiciabilidad coyuntural, colectiva, que permite tener en cuenta legislaciones y prácticas de envergadura y criticarlas con el fin de conseguir la conformidad con la Carta pro futuro; ello no obstante, y como bien ha ilustrado Sudre ${ }^{46}$, podrían cifrarse en numerosas las situaciones generales susceptibles de dar lugar paralelamente a una demandante individual por parte de una víctima: niño autista privado de una educación apropiada, gitano nómada expulsado con nocturnidad de su emplazamiento, guía de turismo con diploma oficial pero agraviado en su profesión frente a sus colegas acreditados por el Estado ${ }^{47}$, etc.

En la reclamación n. ${ }^{\circ}$ 13/2002, el derecho a la educación de los autistas es examinado a la luz de las obligaciones estructurales del Estado. La ONG reclamante reprochaba a Francia «que los niños y los adultos autistas ni ejercen ni

45 DCEDS Confederación de empresas suecas (SN) c. Suecia, de 15 mayo de 2003, reclamación n. ${ }^{\circ}$ 12/2002 (fondo), $\$ 27-31$.

46 SUDRE, Frédéric: «La protection des droits sociaux par la Cour européenne des droits de l'homme: un exercice de "jurisprudence-fiction"?», in Revue trimestrielle des droits de l'homme, $\mathrm{n} .{ }^{\circ}$ 55, Bruxelles 2003, pág. 755 ss, 762 ss.

${ }^{47}$ Cf. DCEDS CEDR c. Italia (n. 27), $\$ 41$ s.; Asociación Internacional Autismo-Europa (AIAE) c. Francia, de 4 noviembre de 2003, reclamación n. ${ }^{\circ}$ 13/2002 (fondo), $\$ 54$; Sindicato nacional de profesiones del turismo (SNPT) c. Francia, de 10 octubre de 2000, reclamación n. ${ }^{\circ}$ 6/1999 (fondo), \$34. 
pueden ejercer de manera efectiva, adecuada y en número suficiente su derecho a ser educados en un medio ordinario o a través de fórmulas de inserción que les permitan disfrutar de un apoyo adecuado en instituciones especializadas que ofrezcan posibilidades educativas y servicios conectados con ellas». Según el ritmo de las reformas emprendidas por dicho Estado, «haría falta un siglo para paliar el déficit de plazas ${ }^{48}$. Parece claro que nos encontrábamos ante una medida estructural costosa - la creación progresiva de centros y de plazas educativas adecuadas para los niños y adultos autistas- Sin embargo, lejos de declararse incompetente, el Comité Europeo de Derechos Sociales precisó que "cuando la realización de uno de los derechos en cuestión sea excepcionalmente compleja y particularmente onerosa, el Estado Parte debe esforzarse en alcanzar los objetivos de la Carta dentro de un plazo razonable, a precio de progresos ponderables, utilizando de la mejor manera los recursos de que disponga ${ }^{49}$.

Además de la llamativa analogía con el artículo 2.1 del Pacto internacional de derechos económicos, sociales y culturales, puede hacerse notar la transición desde obligaciones internacionales de resultado hacia obligaciones de medios, que constriñen al Estado a emplear, de buena fe, sus recursos disponibles con el fin de llegar a un determinado resultado, de ponderar los progresos emprendidos y, sobre todo, de avanzar a un ritmo razonable, lo que no se producía en Francia en el caso de autos. El mismo enfoque se dejó entrever, de manera embrionaria, con relación a la abolición del trabajo de los niños en Portugal, así como con respecto a la creación de emplazamientos adecuados y decentes para los gitanos nómadas y al despliegue de una política de discriminación positiva que permita a los gitanos sedentarios encontrar una vivienda asequible y apropiada en Italia ${ }^{50}$.

\section{B) En el ámbito del CEDH}

El examen del Tribunal de Estrasburgo difícilmente puede permanecer en el exclusivo plano de las situaciones individuales, dado que puede darse el caso de que la «raíz del mal» se sitúe en el terreno de una legislación, de una práctica o de una situación de hecho general, con lo que la sentencia dictada por la alta jurisdicción europea comportará una dimensión institucional más acentuada.

48 DCEDS AIAE c. Francia (n. 47), $\$ 7 \& 22$.

49 DCEDS AIAE c. Francia (n. 47), $\$ 53$. La cursiva es nuestra.

50 Cf. DCEDS Commission internationale des Juristes (CIJ) c. Portugal, de 9 septiembre de 1999, reclamación n. ${ }^{\circ}$ 1/1998 (fondo), $\$ 39$ ss; Centro de Derechos para los Gitanos Europeos (ERRC) c. Grecia, de 8 diciembre de 2004, reclamación n. ${ }^{\circ}$ 15/2003 (fondo), $\$ 21$ ss; CEDR c. Italia (n. 27), $\$ 36 \& 49$. 
Si, como ha explicado Akandji-Kombé, el «Tribunal Europeo de Derechos Humanos ha (...) optado por enfoque binario, más simple, que clasifica las obligaciones de los Estados en dos categorías: obligaciones negativas de un lado $y$, de otro lado, obligaciones positivas ${ }^{51}$, ello no impide consagrar obligaciones positivas de calidad y de intensidad diferentes ${ }^{52}$.

Varias sentencias-piloto del Tribunal Europeo ponen de manifiesto obligaciones positivas de naturaleza institucional: en el asunto Öneryildiz, por ejemplo, el demandante denunciaba que las autoridades turcas no habían adoptado las medidas necesarias para evitar la catástrofe ecológica que acabó con la muerte de nueve de sus familiares (así como de otras treinta personas que vivían en un barrio de chabolas de Estambul): situada en medio de un vertedero de desechos, la chabola en la que el demandante y su familia vivían en la época de los hechos se había visto desbordada por inmundicias tras una explosión de gas metano. Insistiendo así con énfasis en la obligación de informar a la población del barrio chabolista con respecto a los peligros (plenamente conocidos) que representaba la instalación de gas vecina y en la importancia de un marco reglamentario detallado y exigente relativo a la explotación de un vertedero público, el Tribunal Europeo dio un paso más: sobre Turquía pesaba una obligación de prevención general consistente en establecer «dentro de un plazo razonable (...) una instalación de gas adecuada (...) antes que de que la situación deviniera fatal». Lo cual, en efecto, habría "podido constituir una medida eficaz, sin gravar excesivamente los recursos del Estado» ni "conllevar problemas de opciones políticas» de gran alcance. Además, Turquía habría debido «asegurar la coordinación y la cooperación entre las diferentes autoridades administrativas", que se hallaban inmersas en conflictos de competencias, "para que éstas no provocaran que los riesgos de los que habían tenido conocimiento se agravaran hasta el punto de amenazar vidas humanas» ${ }^{53}$. Al omitir la adopción de medidas de precaución

51 AKANDJi-Kombé (n. 30), pág. 5.

52 Dejamos aquí de lado la subobligación de abstecimiento o suministro, que obliga a un Estado a socorrer directamente a las personas vulnerables que son (temporalmente) incapaces de salir adelante sin ayuda exterior. A tal efecto, la jurisprudencia del Tribunal Europeo nos ofrece un ejemplo que ya se ha convertido en clásico, a saber, el derecho (no previsto en el art. 6 CEDH) a la asitencia jurídica gratuita en algunos asuntos civiles: STEDH Airey c. Irlanda, de 9 octubre de 1979, demanda 6289/73, série A32, \$26. Véase asimismo DE SCHUTTER, Olivier: «Linterdépendance des droits et l'interaction des systèmes de protection: les scénarios de système européen de protection des droits fondamentaux», in Droit en quart monde, n. ${ }^{\circ} 28-29$, Bruxelles, 2000, pág. 3 ss, 10; TUlKENS, Françoise: «Les droits sociaux dans la jurisprudence de la nouvelle Cour européenne des droits de l'homme», in Les droits sociaux ou la démolition de quelques poncifs [BENOÎTRohmer, Florence / Grewe, Constance (édit.)], Strasbourg, 2003, pág. 117 ss, 120 s.

53 STEDH Öneryildiz (n. 30), $\$ 90 \& 108$ s. 
formales, tanto de información como materiales, Turquía había violado por tanto el derecho a la vida (artículo $2 \mathrm{CEDH}$ ).

En un supuesto muy similar, el Tribunal examinó las medidas administrativas, legislativas y políticas adoptadas por las autoridades rusas con objeto de proteger la salud ya gravemente afectada de la demandante, quien - como un buen número de habitantes de una ciudad muy populosa - vivía dentro del perímetro de seguridad sanitaria de una fábrica con emisiones muy nocivas. Incluso «teniendo en cuenta el amplio margen de apreciación reconocido al Estado demandado en la materia, el Tribunal concluye que éste no ha sabido establecer un justo equilibrio entre los intereses de la sociedad y el interés de la demandante de poder disfrutar efectivamente de su derecho al respeto de su domicilio y de su vida privada» (artículo $8 \mathrm{CEDH}$ ). Entre las opciones disponibles - realojamiento de la demandante imponiendo los gastos de ello a la fábrica controvertida o «medidas efectivas teniendo en cuenta los intereses de la población local, expuesta a la contaminación, y susceptibles de reconducir el volumen de emisiones industriales a niveles aceptables" - las autoridades rusas habían permanecido culpablemente pasivas ${ }^{54}$. De hecho, la demandante había sido incluida de oficio en una lista de espera para ser realojada en 1999. Ahora bien, seis años más tarde, en el momento del pronunciamiento de la sentencia, ella seguía viviendo dentro del perímetro de la industria contaminante...

Podrían ser mencionados muchos otros ejemplos de sentencias en las que estaban en juego obligaciones de orden estructural. En el marco del presente estudio, nos limitaremos sin embargo a citar solamente uno más: basándose en los artículos 1.1 del Pacto adicional n. ${ }^{\circ} 1$ al CEDH (derecho de propiedad) y 46 $\mathrm{CEDH}$ (fuerza obligatoria y ejecutiva de las sentencias), el Tribunal estimó que la aplicación práctica de la legislación sobre la indemnización o justiprecio de los polacos expropiados de sus bienes situados al otro lado del río Boug tras la Segunda Guerra Mundial constituía una violación del derecho de propiedad. El asunto revelaba una disfunción sistémica de la legislación y la práctica administrativa polacas, en la medida en que un grupo considerable de ciudadanos se encontraba en una situación análoga a la del demandante. «Aunque en principio no corresponde al Tribunal definir cuáles pueden ser las medidas de solución apropiadas para que el Estado demandado cumpla con sus obligaciones», el carácter estructural de las disfunciones exige "medidas generales a nivel nacional». Dichas medidas «deben tomar en consideración a las numerosas personas afectadas" $\mathrm{y}$ "comportar un mecanismo que ofrezca a las personas lesionadas una re-

${ }^{54}$ STEDH Fadeïeva c. Rusia, de 9 junio de 2005, demanda 55723/00, $\$ 132$ ss. 
paración por la violación del Convenio determinada en la presente sentencia». Incidiendo en estos argumentos, el Tribunal remitió a desarrollos que contenían indicaciones sobre las medidas que podrían en su caso estimarse adecuadas ${ }^{55}$.

\subsection{Síntesis}

Lo precedentemente ilustrado evidencia que el modelo simplificador de los tres estratos obligacionales puede ser aplicado a los derechos humanos que figuran tanto en el Convenio Europeo de Derechos Humanos como en la Carta Social Europea Revisada. Si el Comité Europeo de Derechos Sociales no ha desarrollado pragmáticamente una "doctrina de las obligaciones» y si el Tribunal Europeo sólo conoce un modelo dual, no es menos cierto que tanto los derechos sociales como los civiles pueden engendrar los tres géneros de obligaciones anteriormente descritos. A tal efecto, y a título esquemático, resulta interesante trazar la evolución paralela de las jurisprudencias del Tribunal y del Comité. Mientras que, partiendo de un texto de contornos negativos, los esfuerzos creadores del primero «descubrieron» las obligaciones positivas, la práctica del segundo desarrolló algunos aspectos liberales a partir de un texto redactado de manera esencialmente positiva. La confluencia de ambas jurisprudencias no hace sino confirmar que la multiplicidad de los tipos de obligaciones es inherente a todos los derechos humanos.

\section{Entrecruzamiento y referencias cruzadas}

Más allá de la naturaleza de las obligaciones que las prácticas del Tribunal y del Comité han consagrado al interpretar el Convenio Europeo y la Carta Social Europea Revisada, es posible identificar otras formas de acercamiento abiertamente expuestas tanto de uno como de otro lado. Además de una cierta con-

55 STEDH Broniowski c. Polonia (Gran Sala), de 22 junio de 2004, demanda 31443/96, rec. 2004-v, $\$ 189$ \& 193 s. Sin embargo, debe precisarse que las sentencias de este tipo sólo se admiten en presencia de «violaciones que deriven de una situación de carácter estructural», en lo demás, los Estados tienen libertad, «bajo el control del Comité de Ministros del Consejo de Europa, para elegir los medios para cumplir con su obligación jurídica a la vista del artículo 46 del Convenio, siempre que dichos medios sean compatibles con las conclusiones contenidas en la sentencia del Tribunal»: STEDH Monnat c. Suiza, de 21 septiembre de 2006, demanda 73604/01, \$ 84 . Cf. asimismo: STEDH Sejdovic c. Italia (Gran Sala), de 1er marzo de 2006, demanda 56581/00, $\$ 119$ ss. 
vergencia semántica y conceptual (1), es la armonización directa (2) o indirecta (3) - total o parcial — de la protección de los derechos humanos la que presenta un interés particular.

\subsection{La convergencia de métodos y conceptos}

En poco más de diez años de práctica en el ámbito de las reclamaciones colectivas, los conceptos y métodos de interpretación utilizados por el Comité de Estrasburgo han sabido ampliamente retomar y desarrollar las nociones elaboradas por el Tribunal Europeo ${ }^{56}$. Sin pretensión de exhaustividad, bastará con mencionar la noción de «instrumento vivo» que se emplea para calificar la Carta, el concepto de «derechos no teóricos sino efectivos», la creación de «nociones autónomas» o el «margen de apreciación» de los Estados, que va a la par del control europeo ejercido por el Comités7. La mayor parte de estas nociones se refieren a métodos de interpretación devenidos «clásicos» en materia de derechos humanos: la teoría del efecto útil que justifica una interpretación teleológica de la Carta, así como la interpretación denominada evolutiva, que — como si de un efecto de «elasticidad» se tratara- extiende y realza progresivamente los estándares de protección en materia de derechos humanos ${ }^{58}$. Uno de los ejemplos más sobresalientes de la aplicación del método teleológico por parte del Comité Europeo de Derechos Sociales se encuentra en la reclamación n. ${ }^{\circ}$ 14/2003 relativa al derecho a la salud de los «sin papeles». En su párrafo primero, el Anexo de

56 Cf. BRILlat, Régis: «La Charte sociale européenne», in Les droits sociaux ou la démolition de quelques poncifs [BENOÎT-ROHMER, Florence / GREWE, Constance (édit.)], Strasbourg, 2003, pág. $83 \mathrm{ss}, 88 \mathrm{~s}$.

57 Cf. DCEDS CIJ c. Portugal (n. 50), $₫ 32$; SNPT c. Francia (n. 47), $\$ 5$; QCEA c. Grecia (n. 24), $\$ 24$; Confederación francesa de directivos-Confederación general de ejecutivos contra Francia CFE-CGC c. Francia, de 16 noviembre de 2001, reclamación n. ${ }^{\circ}$ 9/2000 (fondo), $\$ 50$; STTK ry y Tehy ry c. Finlandia, de 17 octubre de 2001, reclamación n. ${ }^{\circ}$ 10/2000 (fondo), $\$ 20$; SN c. Suecia (n. 45), $₫ 43$; FIDH c. Francia (n. 26), $\$ 27$; Confederación General del Trabajo (CGT) c. Francia, de 9 febrero de 2004, reclamación n. ${ }^{\circ}$ 22/2003 (admisibilidad), $₫ 4$; CGSP c. Bélgica (n. 43), $₫ 36$; SAGES c. Francia (n. 44), $\$ 38$ s.

58 Cf. AKANDJI-KOMBÉ, Jean-François: «La procédure de réclamation collective dans la Charte sociale européenne - Chronique des décisions de Comité européen des droits sociaux», in Revue trimestrielle des droits de l'homme, n. ${ }^{\circ}$ 48, Bruxelles, 2001, pág. 1035 ss, 1054 s.; CHATTON, Gregor T.: "The Collective Complaints mechanism within the European Social Charter: making economic and social rights really matter", in Les droits de l'homme au Centre - Human rights at the Center [Besson, Samantha / HotTelier, Michel / Werro, Franz (édit.)], Genève, Zurich, Bâle, 2006, pág. 103 ss, 150-155. Véase, p.e., las decisiones: DCEDS AIAE c. Francia (n. 47), $\$ 52$ s.; OMCT c. Portugal (n. 42), $\$ 34$. 
la CSER excluye en principio a los extranjeros «ilegales» del campo de protección personal de la Carta. En la medida en que el Anexo se aplica a un número muy elevado y variado de ámbitos, el Comité juzgó sin embargo — contra litteram, pero conforme al espíritu de la Carta- que la intensidad con la que la cláusula de exclusión debía aplicarse dependía de la importancia de los derechos en juego. En presencia del derecho a la salud, estrechamente vinculado con el derecho a la vida y con la dignidad humana, el Comité efectuó una amplia lectura del alcance del Anexo, llegando a reconocer igualmente las garantías controvertidas a los $«$ sin papeles» ${ }^{59}$.

\subsection{La armonización y refuerzo materiales}

\section{A) Los «asuntos paralelos»: noción}

Desde la introducción del procedimiento de reclamaciones colectivas, pero asimismo en el marco del examen de los informes al que sólo se aludirá incidentalmente en el presente trabajo, ante el Tribunal y el Comité se han ido planteando en diversas ocasiones «asuntos paralelos». Se trata de situaciones que, tratados bajo el ángulo de las disposiciones respectivas del CEDH o de la CSER, suscitan cuestiones análogas, con la sola diferencia de que el Tribunal conoce de ellas a través de las demandas individuales, mientras que el Comité las aborda en un contexto más global, que afecta potencialmente a una pluralidad de personas. Ya se trate de una convergencia de decisiones implícita y, ¿quién sabe?, puramente fortuita, ya se trate de una convergencia manifestada a través de remisiones expresas a la jurisprudencia del otro órgano, el caso es que las referencias del Comité a la jurisprudencia del Tribunal son aún, por el momento, claramente más frecuentes. Es sobre todo en las zonas de yuxtaposición explícitas entre el CEDH y la Carta, especialmente en materia de libertad sindical, de educación, de trabajo forzado o de protección de la vida privada y familiar, en donde semejante armonización material ha podido o podrá tener lugar ${ }^{60}$.

59 DCEDS FIDH c. Francia (n. 26), \$27-32.

${ }^{60}$ Cf., p.e., las disposiciones siguientes: art. $4 \mathrm{CEDH} /$ art. $1 \$ 2$ CSER: prohibición del trabajo forzado; art. $8 \mathrm{CEDH} /$ art. 7, 15-17 CSER (protección de la familia, de los niños y de las personas con discapacidad) \& art. 31 CSER (vivienda); art. $11 \mathrm{CEDH} /$ art. $5 \& 6 \mathrm{CSE}(\mathrm{R})$ (derechos sindicales); art. 2 Prot. n. ${ }^{\circ} 1$ al CEDH / art. 17 CSER (derecho a la educación), etc. 
B) Las convergencias implícitas

A título de convergencias implícitas, de las que se ignora si son voluntarias, bastaría con mencionar dos ejemplos recientes: en el asunto Zarb Adami, el demandante denunciaba que la función de jurado que le habían asignado las autoridades maltesas en diversas ocasiones, vulneraba la prohibición de trabajo forzado y obligatorio contenido en el artículo $4 \mathrm{CEDH}$. Incluso si, como tal, la función de jurado se incluye en la excepción al campo de aplicación de dicha disposición, en el sentido del artículo 4.3.d) CEDH, el Tribunal declaró que Malta había violado dicho párrafo en conjunción con el artículo 14 CEDH. En efecto, «un trabajo normal en sí mismo puede revelarse anormal [ $y$ por tanto reintegrar el artículo 4 CEDH] si la discriminación se basa en la elección de grupos o de individuos obligados a cumplirlo». In casu, las autoridades de Malta casi se limitaban a reclutar, en la práctica, a jurados masculinos, lo que fue considerado discriminatorio por el Tribunal ${ }^{61}$. Ahora bien, el estudio simultáneo de la decisión del Comité Europeo de Derechos Sociales en el asunto n. ${ }^{\circ}$ 8/2000 sobre la libertad de trabajar de los objetores de conciencia griegos viene a introducir el criterio de la «normalidad» del trabajo efectuado, normalidad que no quedaba garantizada por un servicio excesivamente largo y que justificaba, por ello mismo, la aplicación del artículo 1.2 CSE bajo un ángulo diverso ${ }^{62}$.

Los asuntos Siliadin contra Francia y Comisión Internacional de Juristas contra Portugal merecen ser analizados como convergentes en el sentido de que ambos dan pie a que los artículos 4 CEDH (trabajo forzado) y 7.1 CSE (edad mínima para trabajar) impregnen los ámbitos informales de trabajo. Mientras que la sentencia Siliadin extiende, mediante las obligaciones positivas, el ámbito de protección de la prohibición del trabajo forzado a la "esclavitud doméstica» y exige el establecimiento de mecanismo procedimentales eficaces ${ }^{63}$, la decisión CIJ contra Portugal incluye el trabajo a domicilio y la ayuda familiar en el ámbito del artículo 7.1 CSE, obligando por esta vía a la inspección de trabajo y a los servicios socio-educativos de los Estados a hacer aplicar la prohibición del trabajo ilegal de los niños ${ }^{64}$.

${ }^{61}$ STEDH Zarb Adami c. Malta, de 20 junio de 2006, demanda 17209/02, $\$ 44$ s. Esta jurisprudencia se inscribe en la línea adecuada marcada por las sentencias Van der Mussele c. Bélgica, de 23 noviembre de 1983, demanda 8919/80, série A70, \$43, y Karlheinz Schmidt c. Alemania, de 18 julio de 1994, demanda 13580/88, série A291-B, \$ 22 ss.

${ }^{62}$ DCEDS QCEA c. Grecia (n. 24), \$22-25.

63 STEDH Siliadin (n. 30), $\$ 148$.

${ }^{64}$ DCEDS CIJ c. Portugal (n. 50), $\$ 27$ s.: «Entra asimismo en el ámbito del artículo 7 , apdo. 1 el trabajo efectuado por los niños en el marco de la familia (ayuda familiar), incluso cuan- 


\section{C) Las referencias a la jurisprudencia del Tribunal}

Las remisiones que opera el Comité Europeo de Derechos Sociales a la jurisprudencia del Tribunal Europeo de Derechos Humanos están omnipresentes en las decisiones de fondo y confirman la voluntad del Comité de realizar la idea de de un sistema europeo integrado de derecho humanos que reúna, en pie de igualdad, derechos civiles y derechos sociales ${ }^{65}$. Más arriba hemos mencionado las reclamaciones presentadas por la Organización Mundial Contra la Tortura para hacer prohibir - tanto en el plano legislativo como en la praxis- los castigos corporales en la escuela, en las instituciones de guarda de niños y en el seno de las familias. En un supuesto relativo a Irlanda, la defensa consuetudinaria del «castigo razonable» fue considerada como no conforme a la Carta. En un caso concreto de aplicación, el asunto A. contra Reino Unido, el Tribunal había juzgado que la ley inglesa, que contenía igualmente semejante excepción consuetudinaria, no había podido proteger adecuadamente la integridad física y moral del demandante, a quien su padrastro propinaba golpes con un bastón ${ }^{66}$.

En el asunto n. ${ }^{\circ} 8 / 2000$, el Comité integró el artículo 4.3.b) CEDH en su interpretación del artículo 1.2 CSE con el fin de constatar que el servicio civil sustitutorio de los objetores de conciencia no entraba en el ámbito de aplicación de dicha disposición bajo el ángulo del trabajo forzado ${ }^{67}$. En el asunto n. ${ }^{\circ}$ 16/2003, el Comité estimó, basándose en la sentencia Cantoni, que la circunstancia de que una disposición nacional controvertida se inspire en una directiva comunitaria no la sustrae al imperio de la Carta ${ }^{68}$.

En el asunto n. ${ }^{\circ} 15 / 2003$, el Comité citó extensivamente la sentencia Connors con objeto de deducir de ella la obligación para un Estado de adoptar medidas positivas a favor de la minoría gitana y de su modo de vida particu-

do dicho trabajo no sea desempeñado para una empresa en el sentido jurídico y económico del término y aunque esos niños no ocupen un verdadero empleo".

${ }_{65}$ Véase especialmente: DCEDS QCEA c. Grecia (n. 24), $\$ 22$; AIAE c. Francia (n. 47), $₫$ 52; ERRC c. Grecia (n. 50), $\$ 20$; Confederación francesa de directivos-Confederación general de ejecutivos contra Francia (CFE-CGC) c. Francia, de 12 octubre de 2004, reclamación n. ${ }^{\circ}$ 16/2003 (fondo), $\$ 30$; OMCT c. Grecia (n. 42), \$31; OMCT c. Irlanda (n. 41), \$ 63; OMCT c. Italia (n. 42), $\$ 41$; OMCT c. Portugal (n. 42), $\$ 34$; OMCT c. Bélgica (n. 42), $\$ 38$; SAGES c. Francia (n. 44), $\$ 34$.

${ }^{66}$ STEDH A. c. Reino Unido (n. 30), $\$ 24$ (cf. supra); DCEDS OMCT c. Irlanda (n. 41), $\$ 65 \mathrm{~s}$.

67 DCEDS QCEA c. Grecia (n. 24), $\$ 22$.

68 STEDH Cantoni c. Francia (Gran Sala), de 15 noviembre de 1996, demanda 17862/91, rec. 1996-v, \$30; DCEDS CFE-CGC c. Francia, reclamación n. ${ }^{\circ}$ 16/2003 (n. 65), \$30. 
lar ${ }^{69}$. El asunto $n .^{\circ}$ 15/2003 pone de relieve que el Comité no vacila a la hora de tomar al pie de la letra algunos obiter dicta del Tribunal Europeo con el fin de desarrollar su propia jurisprudencia más allá de los estándares realmente establecidos por aquél. En efecto, si el Tribunal consagró - como prolongación de las sentencias Buckley y Chapman - una «obligación positiva de facilitar el modo de vida gitana», así como el deber de «otorgar una atención especial» a dicha minoría vulnerable, y ello "tanto en el marco reglamentario pertinente como en la toma de decisiones en cada caso preciso", en cambio no había extraído las consecuencias prácticas requeridas y siempre se había refugiado tras el margen de apreciación acordado a los Estados para no admitir la existencia de violación del artículo $8 \mathrm{CEDH}^{70}$. En cuanto a la constatación de violación en el asunto Connors, el Tribunal se refería al defecto de garantías procedimentales adecuadas que permitiera a un gitano semi-sedentario defenderse contra una expulsión forzosa absolutamente sumaria de su lugar de acampada duradero $^{71}$. Aunque el Tribunal incorpore algunas consideraciones vinculadas con las tradiciones ancestrales de los gitanos, no se aventura sin embargo a entrar en el terreno de las medidas de discriminación positivas, pese a haberlas anunciado en sus dicta. Por el contrario, el Comité no eludirá entrar en dicho terreno, para así imponer a Grecia y a Italia, dentro de límites razonables, una serie de obligaciones encaminadas específicamente a facilitar el ejercicio del derecho a la vivienda, en todas sus formas, por parte de los gitanos ${ }^{72}$.

D) Las referencias a la jurisprudencia (sobre reclamaciones y sobre informes) del Comité

Si bien es evidente que las disposiciones de la Carta no pueden, so pena de incurrir en inadmisibilidad ratione materiae, ser directamente invocadas y aplicadas por el Tribunal Europeo ${ }^{73}$, ni correlativamente las disposiciones del CEDH

${ }^{69}$ STEDH Connors c. Reino Unido, de 27 mayo de 2004, demanda 66746/01, $\$ 84$; DCEDS ERRC c. Grecia (n. 50), \$20.

70 STEDH Chapman c. Reino Unido (Gran Sala), de 18 enero de 2001, demanda 27238/95, rec. 2001-i, $\$ 96 \&$ 114; Buckley c. Reino Unido, de 25 septiembre de 1996, demanda 20348/92, rec. 1996-iv, $\$ 76,80 \& 84$.

${ }^{71}$ STEDH Connors (n. 69), $\$ 94$ s. Esta argumentación tiene su equivalente en la DCEDS CEDR c. Italia, (n. 27), $\$ 41$ s., con relación al tipo de expulsiones forzosas practicadas por Italia. Véase también: DCEDS ERRC c. Grecia, (n. 50), $\$ 50$ s.

72 DCEDS ERRC c. Grecia (n. 50), $\$ 42$ s.; CEDR c. Italia (n. 27), $\$ 37 \& 45$ s.

73 Véase, p.e.: Comisión Europea de Derechos Humanos, Decisión M.K. c. Grecia, de 4 abril de 1994, demanda 20668/92, \$4; DTEDH (Decisión del Tribunal Europeo de Derechos Hu- 
por el Comité Europeo de Derechos Sociales ${ }^{74}$, la jurisprudencia del Tribunal encierra algunos ejemplos interesantes de interpretación conforme a la jurisprudencia del Comité, o cuando menos, a las disposiciones mismas de la Carta.

En el asunto Zielinski y otros, el Tribunal declaró que el artículo 6.1. CEDH era aplicable a un litigio entre cajas locales de seguro de enfermedad de Derecho privado y de su personal: en efecto, estos «organismos de seguridad social realizan una misión de servicio público» de la que pueden resultar obligaciones impuestas por la Carta Social Europea, y quedan situados bajo tutela ministerial. La intervención del legislador francés —-sancionada por el Consejo Constitucional - tendente a reducir a la nada los procedimientos judiciales sustanciados con ocasión de indemnizaciones muy costosas debidas a los demandantes era contraria a la exigencia de un proceso equitativo ${ }^{75}$. En su decisión Stec y otros, la Gran Sala clarificó su jurisprudencia Gaygusuz según la cual los importes debidos por razón de una prestación social no contributiva (por ejemplo, financiada por el sistema impositivo general y no por medio de cotizaciones sociales) entran en la noción de «bienes» en el sentido del artículo 1 del Protocolo n. ${ }^{\circ} 1$ al CEDH. Frente al argumento del Gobierno británico según el cual semejante inclusión privaría a la Carta Social de toda utilidad a la luz del derecho a la seguridad social, el Tribunal Europeo respondió que «no cabe descartar tal o cual interpretación del Convenio por el simple motivo de que al adoptarla se correría el riesgo de caer en la esfera de los derechos económicos y sociales; ningún compartimiento estanco separa dicha esfera del ámbito del Convenio». Además, el CEDH no obliga a los Estados a instaurar un régimen de protección social; luego, sólo en caso de que ellos decidan libremente prever el pago automático de una prestación social bajo ciertas condiciones «dicha legislación deberá ser considerada como generadora de un interés patrimonial» en el sentido del artículo 1 del Protocolo n. ${ }^{\circ}$ al $\mathrm{CEDH}^{76}$.

manos) J.F. c. Francia, de 20 abril de 1999, demanda 39616/98, § 3; Jitka Zehnalova y Otto Zehnal c. República Checa, de 14 mayo de 2002, demanda 38621/97, rec. 2002-v, título n. ${ }^{\circ} 2$.

${ }^{74}$ DCEDS SAIGI c. Francia (n. 39), $\$ 6$ s.; sin embargo, la decisión de inadmisibilidad se basó ante todo en el carácter de demanda individual de la reclamación.

75 STEDH Zielinski y Pradal y Gonzalez y otros (Gran Sala), de 28 octubre de 1999, demanda 24846/94; 34165/96 a 34173/96, rec. 1999-vii, $\$ 59$ s.

76 DTEDH Stec y otros c. Reino Unido (Gran Sala), de 6 julio de 2005, demanda 65731/01; 65900/01, \$ 48 s. \& 52 s.; Gaygusuz c. Austria, de 16 septiembre de 1996, demanda 17371/90, rec. 1996-iv. Cf. DAUGAREILH, Isabelle: «La Convention européenne de sauvegarde des droits de l'homme et des libertés fondamentales et la protection sociale», in Revue trimestrielle de droit européen, n. ${ }^{\circ}$ 1, Bruxelles, 2001, pág. 123 ss, 128 s.; SUDRE, Frédéric: «La protection des droits sociaux par la Convention européenne des droits de l'homme», in Les nouveaux droits de 
En los asuntos Campagnano, Albanese y Vitiello contra Italia, el Tribunal estimó que en razón de «la naturaleza automática de la inscripción del nombre del quebrado en el registro y de la ausencia de una evaluación y de un control jurisdiccionales sobre la aplicación de (las numerosas incapacidades civiles) en dicho ámbito, así como del lapso de tiempo previsto para la obtención de la rehabilitación", la ley italiana sobre la quiebra violaba el derecho al respeto de la vida privada de los demandantes ${ }^{77}$. Por lo demás, para declarar aplicable el artículo $8 \mathrm{CEDH}$, el Tribunal había entendido que la vida privada «engloba el derecho del individuo de entablar y desarrollar relaciones con sus semejantes, inclusive en el ámbito profesional y comercial». Al fin y al cabo, «es en el ámbito laboral en donde las personas entablan un buen número de relaciones con el mundo exterior», de suerte que "la prohibición de ocupar un gran número de puestos de trabajo en el sector privado afecta a la 'vida privada' (...), teniendo en cuenta asimismo el artículo 1.2 de la Carta» revisada ${ }^{78}$.

Mientras que los ejemplos precedentes ponen de manifiesto una extensión del ámbito de aplicación del CEDH por medio (entre otras) de referencias a la Carta, los asuntos siguientes denotan esfuerzos de armonización mucho más intensos. Tres ámbitos permiten ilustrarlo a continuación: en el asunto Koua Poirrez, el demandante padecía una discapacidad física y le fue reconocido un porcentaje de incapacidad del $80 \%$ por las autoridades francesas. Al solicitar el reconocimiento de "la prestación para los adultos discapacitados», le fue denegada por no tener nacionalidad francesa o, alternativamente, la nacionalidad de un Estado con el que Francia hubiera suscrito un acuerdo de reciprocidad. La abolición de esta condición por una ley posterior permitió al demandante percibir las prestaciones controvertidas de cara al futuro; por tanto, su denuncia versaba sobre el período anterior a la mencionada ley. Siguiendo la estela de la sentencia Gaygusuz, la diferencia de trato de la que fue víctima el demandante era claramente constitutiva de una discriminación en el disfrute de un derecho pa-

l'homme en Europe - XI Congreso 29-31 mayo de 1997 en Palma de Mallorca, Bruxelles, 1999, pág. 103 ss, 123.

77 STEDH Vitiello c. Italia, de 23 marzo de 2006, demanda 77962/01, $\$ 62$; Campagnano c. Italia, de 23 marzo de 2006, demanda 77955/01, \$66; Albanese c. Italia, de 23 marzo de 2006, demanda $77924 / 01, \$ 66$.

${ }_{78}$ STEDH Vitiello (n. 77), $₫ 47$; Campagnano (n. 77), $\$ 53$; Albanese (n. 77), $\$ 53$, con remisiones a las SSTEDH Pretty c. Reino Unido, de 29 abril de 2002, demanda 2346/02, rec. 2002-iii, \$61 y Niemietz c. Alemania, de 16 diciembre de 1992, demanda 13710/88, série A251B, $\$ 29$. Véase asimismo, entre otras: SSTEDH Lykourezos c. Grecia, de 15 junio de 2006, demanda 33554/03, $\$ 3$ del voto particular discrepante del juez Spielmann al que se adhiere la jueza Tulkens; DTEDH Molka c. Polonia, de 11 abril de 2006, demanda 56550/00, título n. ${ }^{\circ} 2$. 
trimonial, siendo el criterio de la nacionalidad el único obstáculo que impedía al demandante disfrutar de dicha prestación ${ }^{79}$. Merece la pena subrayar que, para declarar el criterio de la nacionalidad prima facie como no conforme con el artículo $14 \mathrm{CEDH}-\mathrm{y}$ ello particularmente en presencia de una persona con discapacidad-, el Tribunal se apoyó expresamente en las Conclusiones del Comité Europeo de Derechos Sociales adoptadas en el marco del procedimiento de examen de informes. Este último sólo había declarado el Código francés de la seguridad social conforme al artículo 12.4 CSE (derecho a la seguridad social) una vez que Francia hubo derogado la condición de reciprocidad para la concesión de la prestación a los adultos discapacitados ${ }^{80}$.

El asunto Sidabras y Dziautas contra Lituania planteó, por su parte, el problema relativo a si la revocación de los demandantes de sus puestos de trabajo en el seno de la Administración de Hacienda tras la intervención del ministerio público en razón de su actividad pasada en los servicios de la KGB soviética, se justificaba o no a la luz de los artículos 8 y $14 \mathrm{CEDH}$. Tras constatar una diferencia de trato con respecto a los nacionales lituanos que no habían trabajado para ese controvertido servicio secreto, el Tribunal admitió igualmente la aplicación del artículo $8 \mathrm{CEDH}$. En efecto, «una prohibición general de ocupar un empleo en el sector privado $^{81}$ atenta claramente contra la 'vida privada'. [El Tribunal] confiere un peso particular a este respecto al artículo 1.2 de la Carta (...) y a la interpretación que de él se ha dado [por el Comité Europeo de Derechos Sociales], así como a los textos adoptados por la OIT (...). El Tribunal recuerda adicionalmente que ningún compartimiento estanco separa la esfera de los derechos económicos y sociales del ámbito del Convenio " ${ }^{82}$. En el caso de autos, el Tribunal se basó en los criterios de verificación desarrollados por el Co-

79 STEDH Koua Poirrez c. Francia, de 30 septiembre de 2003, demanda 40892/98, rec. 2003-x, \$ 37-42 \& 46-50; Gaygusuz (n. 76), \$ 41.

80 STEDH Koua Poirrez (n. 79), $\$ 29 \&$ 39. Cf. las Conclusiones del Comité Europeo de Derechos Sociales C/CSE XV-1, t. I, pág. 277 (Francia).

${ }^{81}$ En la realidad, la prohibición establecida por la Ley lituana sobre la KGB versaa sobre el conjunto del sector público y algunos empleos en el sector privado.

82 STEDH Sidabras y Dziautas c. Lituania, de 27 julio de 2004, demanda 55480/00; 59330/00, rec. 2004- viii, $\$ 47$ ss, y prosigue: «Ciertamente, esta prohición no les impide ejercer algunos tipos de actividades profesionales, pero afecta hasta tal punto su capacidad de entablar relaciones con el mundo exterior y les causa dificultades tan graves en cuanto a la posibilidad de ganarse la vida que ello tiene repercusiones evidentes en su vida privada». Sin contar que sus actividades anteriores, indudablemente elegidas de modo sesgado, "constituyen para ellos una fuente de problemas cotidianos» y de estigmatización social. Ver, en cuanto a la ausencia de "copartimientos estancos», la STEDH Airey (n. 52), \$26. 
mité Europeo de Derechos Sociales bajo el ángulo de la Carta, así como por la Comisión de expertos para la aplicación de los convenios y recomendaciones de la OIT bajo el ángulo del Convenio n. ${ }^{\circ} \mathrm{C}-111 / 1958$ relativo a la discriminación en el empleo y la profesión. Mientras que el órgano europeo, en sus Conclusiones referentes a la revocación en Alemania de funcionarios de la ex RDA había criticado el hecho de que la ley nacional no contuviera una «definición precisa de las funciones de las que podían ser excluidas, bien por la negativa a contratarlas bien por despido, las personas en razón de sus actividades políticas pasadas ${ }^{83}$, la mencionada Comisión de expertos de la OIT había hecho lo propio con relación al informe letón, dado que "las exclusiones definidas [por la legislación de Letonia] se aplican al conjunto de la función pública y de la policía, y no a empleos, funciones o tareas claramente definidas ${ }^{84}$. Incidiendo en dichos argumentos, y tras haber efectuado una cuidadosa ponderación de los intereses en juego, el Tribunal europeo estimó la demanda tras entender que las exclusiones previstas por la ley lituana sobre la KGB habían sido formuladas de manera demasiado vaga, que dichas restricciones se aplicaban igualmente a una parte importante del sector profesional y que la ley había sido adoptada extemporáneamente, concretamente una decena de años más tarde de que los demandantes hubieran abandonado la KGB y de que Lituania hubiese recuperado su independencia ${ }^{85}$.

Finalmente, los asuntos acumulados Sørensen y Rasmussen revisten una importancia particular en el ámbito privilegiado que representa la libertad sindical, consagrada en los dos textos europeos de protección de los derechos humanos ${ }^{86}$.

83 Conclusiones del Comité Europeo de Derechos Sociales C/CSE XVI-1, t. I, pág. 256 (Alemania). Lo que, en el caso de autos, vino a constituir una práctica «no necesaria en una sociedad democrática», en el sentido del artículo 31 CSE (art. G $\$ 1$ CSER).

${ }^{84}$ Comisión de expertos para la aplicación de los convenios y recomendaciones de la OIT, observación individual relativa al Convenio n. ${ }^{\circ} 111 / 1958$, discriminación (empleo y profesión), Letonia, Ginebra, 2002, Ilolex n. ${ }^{\circ} 062002 \mathrm{LVA} 111, \$ 6$ s.

85 STEDH Sidabras y Dziautas (n. 82), $\$ 57-60$ : «... las restricciones impuestos por el Estado a las expectativas de empleo de una persona en una empresa del sector privado por falta de lealtad hacia el Estado no pueden justificarse (...) de la misma manera que las restricciones al acceso a la función pública»; «... con la excepción de la mención a los 'abogados' y 'notarios', la ley no define en modo alguno las tareas, funciones o empleos particulares que se prohíbe ejercer a los demandantes. Por ello, resulta imposible deterinar si existe una conexión razonable entre los puestos afectados y los fines legítimos perseguidos por la prohibición de ocupar esos puestos. Según el Tribunal, la legislación controvertida queda desprovista de las salvaguardias necesarias para evitar toda discriminación y para garantizar un control jurisdiccional adecuado y apropiado de la decisión de infligir semejantes restricciones».

${ }^{86}$ Art. 5 \& 6 CSE(R) y art. $11 \mathrm{CEDH}$. 
En su jurisprudencia más antigua, el Tribunal de Estrasburgo en un primer momento había rechazado pronunciarse "en abstracto» sobre la convencionalidad de las cláusulas de seguridad sindical anteriores y posteriores a la contratación ("closed-shop agreements»), y había dejado entender que la obligación impuesta a los empleados de afiliarse a un sindicato predeterminado en virtud de un convenio colectivo podía resultar aceptable según los $\operatorname{casos}^{87}$. Ahora bien, en su procedimiento sobre informes, así como en el marco de la reclamación colectiva n. ${ }^{\circ} 12 / 2002^{88}$, el Comité Europeo de Derechos Sociales había condenado constantemente dichas cláusulas, juzgadas manifiestamente contrarias al derecho de asociación negativo, y había instado a los Estados que las autorizaban todavía a proceder a su inmediata derogación.

Ciertamente, en un supuesto más reciente, el Tribunal —a la vista de las jurisprudencias del Comité Europeo de Derechos Sociales y del Comité de libertad sindical de la OIT - había despejado un "grado creciente de consenso" en torno al carácter insólito de las cláusulas de seguridad sindical posteriores a la contratación ${ }^{89}$; pero subsistían las cláusulas anteriores a la contratación, más frecuentes en la práctica. El golpe de gracia a toda cláusula de seguridad sindical, incluida la anterior a la contratación, fue por tanto asestado por la sentencia $S \emptyset$ rensen y Rasmussen, a tenor de la cual el Tribunal Europeo se basó en la evolución general de la sociedad y, con cita expresa de la reclamación n. ${ }^{\circ} 12 / 2002$, en la evolución del Derecho internacional, para declarar tales cláusulas como incompatibles con el derecho de sindicación negativo de los demandantes ${ }^{90}$. Resulta innegable que las críticas persistentes del Comité y que su decisión sobre dicha reclamación han jugado en esta sede un papel decisivo con respecto al giro jurisprudencial operado por el Tribunal Europeo.

87 STEDH Sibson c. Reino Unido, de 20 abril de 1993, demanda 14327/88, série A258-a, $\$ 29$ s.; Young, James y Webster c. Reino Unido, de 13 agosto de 1981, demanda 7601/76; 7806/77, série A44, $\$ 52$ s. No abordaremos la STEDH Gustafsson c. Suecia (Gran Sala), de 25 abril de 1996, demanda 15573/89, rec. 1996-ii, cuyos presupuestos fácticos eran absolutamente particulares.

88 DCEDS SN c. Suecia (n. 45), $\$ 27-30$. Ver también, p.e., las Conclusiones del Comité Europeo de Derehos Sociales C/CSE 2004-2, pág. 428.

${ }^{89}$ STEDH Sigurdur A. Sigurjonsson c. Islandia, de 30 junio de 1993, demanda 16130/90, série A264, \$35\& 41 .

90 STEDH Sørensen y Rasmussen c. Dinamarca (Gran Sala), de 11 enero de 2006, asuntos acumulados, demandas 52562/99 y 52620/99, \$59-77. 


\section{Los límites a la armonización autónoma}

Por muy dinámicos que sean en el momento presente, los esfuerzos que realizan el Tribunal Europeo y el Comité Europeo de Derechos Sociales para hacer interactuar y converger sus jurisprudencias recíprocas tropiezan con barreras objetivas cuya posibilidad real de franquear resulta realmente difícil.

\subsection{Los límites de redacción}

Toda convergencia de una cierta amplitud presupone, a nuestro modo de ver, la existencia de puntos de contactos sobre los que basarse. A tal efecto, si bien es cierto que tanto el Convenio Europeo como la Carta Social contienen algunas disposiciones gemelas, no es menos cierto que su formulación no les permite siempre consagrar la interpretación que ha sido dada en el seno del otro sistema convencional. El ejemplo de la libertad sindical nos parece de los más flagrantes ${ }^{91}$. Así, el artículo 11.1 CEDH presenta la libertad sindical como una forma o un aspecto particular de la libertad de asociación; no asegura a los miembros de un sindicato un tratamiento preciso por parte del Estado. Desde el momento en que el Estado ofrezca a los sindicatos un medio entre otros posibles para ser oídos y defender los intereses de sus miembros, las acciones u omisiones del Estado se encuentran como regla general comprendidas dentro del amplio margen de apreciación nacional concedido por el Tribunal Europeo.

Pese a que el Tribunal Europeo efectúe una lectura del artículo $11 \mathrm{CEDH}$ a la luz de la CSER, sólo de forma rara osa extraer de aquél una obligación precisa con cargo al Estado, como sería un derecho a la consulta paritaria, el derecho de huelga, las negociaciones colectivas tendentes a concluir un convenio entre los interlocutores sociales, el derecho al beneficio de determinadas ventajas sociales, etc. ${ }^{92}$.

91 Art. $11 \S 1 \mathrm{CEDH}$ : «Toda persona tiene derecho a la libertad de reunión pacífica y a la libertad de asociación, incluido el derecho de fundar con otros sindicatos y de afiliarse a los mismos para la defensa de sus intereses». Podría igualmente citarse el art. 2 Prot. n. ${ }^{\circ} 1$ al CEDH (derecho a la instrucción), el cual en principio sólo reconoce el acceso a las instituciones escolares preexistentes en un Estado, sin obligar a este último, tal como sí lo exige la Carta, a construir nuevos centros o a subvencionar a los que tengan necesidad. Cf. STEDH Asunto lingüístico belga (n. 28), $\$$ 7; en comparación con la DCEDS AIAE c. Francia (n. 47), $\$ 49$.

92 Cf., especialmente: SSTEDH Tüm Haber Sen y Cinar c. Turquía, de 21 febrero de 2006, demanda 28602/95,\$28; Wilson, Unión Nacional de Periodistas y otros c. Reino Unido, de 2 julio de 2002, demanda 30668/96; 30671/96 y 30678/96, rec. 2002-v, $\$ 42$; Sindicato sueco de conductores de locomotoras c. Suecia, de 6 febrero de 1976, demanda 5614/72, \$39; 
Aunque insatisfactorio en cuanto al resultado concreto alcanzado, la decisión de inadmisibilidad dictada en el asunto FSTO conduce a pensar que el Tribunal Europeo se ha decantado sensiblemente por reducir el margen de apreciación estatal en materia de derecho de huelga, uno de los más importantes instrumentos tendentes a proteger los intereses profesionales de un sindicato y de sus miembros. En el caso de autos, en efecto, el Tribunal Europeo había procedido a un examen minucioso - pero a nuestro entender mal ponderado a la vista de la jurisprudencia del Comité Europeo de Derechos Sociales y de los órganos de la OIT - del conjunto de los intereses en juego, para llegar a la sorprendente conclusión de que la demanda era... manifiestamente infundada ${ }^{93}$.

\subsection{Los límites inherentes a la protección indirecta o conexa ("par ricochet»)}

La jurisprudencia del Tribunal Europeo ha abierto, en estas últimas décadas, la vía a la protección indirecta ("par ricochet») de algunos derechos sociales. No nos resulta posible desarrollar este ámbito específico en el marco del presente estudio ${ }^{94}$. Si acaso, nos limitaremos a recordar que algunas disposiciones materiales y procedimentales del Convenio ya se extienden —en pro de una extensión pretoriana de su ámbito de aplicación - a algunos aspectos del campo social, para conferirle una protección indirecta. Por ejemplo, la vertiente civil del artículo $6 \mathrm{CEDH}$ cubre los valores patrimoniales y permite así a los particulares tener el beneficio de un procedimiento judicial equitativo, entre otros ámbitos, en el terreno de las pensiones sociales.

El artículo 1 del Protocolo n. ${ }^{\circ} 1$ al CEDH, que constituye en sí un derecho mixto, ya abarca las prestaciones sociales tanto contributivas como no contri-

Schmidt y Dahlström c. Suecia, de 6 febrero de 1976, demanda 5589/72, $\$ 34$ ss; Sindicato nacional de la policía belga c. Bélgica, de 27 octubre de 1975, demanda 4464/70, $\$ 38$. DTEDH Juan Sanchez Navajas c. España, de 21 junio de 2001, demanda 57442/00, rec. 2001-vi, $\$ 2$; Dev Madsen Sen c. Turquía, de 9 diciembre de 1999, demanda 32980/96, $\$ 5$ (fundamentos jurídicos).

93 DTEDH Federación de los sindicatos de trabajadores offshore y otros c. Noruega, de 27 junio de 2002, demanda 38190/97, rec. 2002-vi, $\$ 2$ (fundamentos jurídicos). Sin embargo, se introduce la siguente matización: «... el Tribunal subraya que su decisión en el caso de autos no debe ser interpretada en el sentido de significar que un sistema de recurso obligatorio al arbitrage para poner fin a huelgas legales sea juzgado proporcionado en todos los casos en los que se ejerza una presión económica». Cf. HARRIS / DARCY (n. 4), pág. 108.

${ }^{44}$ Nos remitimos a las contribuciones siguientes: KOCH (n. 12), pág. 96 ss; SUDRE (n. 46), pág. 760 ss; SUDRE, Frédéric: «La "perméabilité» de la Convention européenne des droits de l'homme aux droits sociaux", in Pouvoir et Liberté - Études offertes à Jacques Mourgeon, Bruxelles 1998, pág. 467 ss 469 ss; TULKENS (n. 52), pág. 117 ss. 
butivas que sean reconocidas por la legislación de un Estado, cuando las condiciones para su disfrute sean cumplidas ${ }^{95}$. Los artículos 2, 3 y $8 \mathrm{CEDH}$ protegen, especialmente, determinados aspectos del derecho a la salud. Del mismo modo, el artículo 1 del Protocolo n. ${ }^{\circ} 12$ al CEDH, que prohíbe cualquier forma de discriminación en el disfrute de los derechos que se deriven de la «ley» (nacional e internacional) autoriza al Tribunal Europeo a verificar si el Derecho social de un Estado, incluidas las disposiciones de la CSER, ha sido aplicado de manera no discriminatoria ${ }^{96}$.

En cualquier caso, es preciso concluir que las citadas disposiciones del $\mathrm{CEDH}$ no garantizan, como tales, una legislación social, o siquiera un derecho social fundamental; las mismas sólo entran en juego cuando un Estado decide consagrar tal derecho. En tal caso, esas disposiciones velan por la accesibilidad no discriminatoria a dicho derecho, así como por la instauración de garantías procesales para el caso de denegación o de violación ${ }^{97}$.

\subsection{Los límites derivados del mecanismo de control}

La aproximación inherente a los dos sistemas convencionales continuará siendo diferente mientras la Carta no se dote de un mecanismo de demandas individuales ${ }^{98}$, y correlativamente mientras que el Tribunal Europeo no conozca un sistema de reclamaciones colectivas. Incluso aunque, como ya hemos visto, las fronteras entre ambos métodos de examen no queden siempre claramente trazadas, el Comité adopta una perspectiva tendencialmente colectiva y situacional que no admite el recurso individual ${ }^{99}$, en tanto que el Tribunal Europeo analiza

95 ... o cuando una condición discriminaria comportara un obstáculo indebido (art. 14 CEDH). Cf. DTEDH Stec y otros (n. 76), $\$ 48$ s. \& 52 s.; Gaygusuz (n. 76).

${ }^{6}$ P.e., SUDRE (n. 46), pág. 768 ss; TRECHSEL, Stefan, «Überlegungen zum verhältnis zwischen art. 14 emrK und dem 12. Zusatzprotokoll», in Gleichheit und nichtdiskriminierung im nationalen und internationalen menschenrechtsschutz [WOLFRUM, Rüdiger (édit.)], Berlin et al. 2003, pág. 119 ss, 126 ss.

${ }^{7}$ Cf. Sudre (n. 46), pág. 775.

98 Cf. la propuesta, que por el momento sigue siendo letra muerta, de crear un Tribunal Europeo de Derechos Sociales fundamentales o de añadir una Sala Social al Tribunal Europeo de Derechos Humanos: WASESCHA, Luzius: Le système de contrôle de l'application de la Charte sociale européenne, thèse, Genève 1980, pág. 264 ss.

99 DCEDS SAIGI c. Francia (n. 39), $₫$ 8: «El Comité observa que la reclamación pone en entredicho, no tanto normas vigentes en un Estado, sino la manera en la que esas reglas han sido aplicadas en un caso particular durante un procedimiento que ha durado ocho años ante jurisdicciones administrativas y penales, así como ante instancias disciplinarias. Ello, en el caso presente, no es competencia del Comité». 
el caso específico del demandante, el cual no está autorizado a introducir una $a c$ tio popularis ${ }^{100}$. Así, algunos límites a la convergencia se derivan directamente del mecanismo de protección establecido.

A este respecto, merece la pena detenerse en la sentencia Botta y en las demás sentencias dictadas a propósito de demandas relativas al derecho de acceso de personas con discapacidad a infraestructuras públicas (artículo $8 \mathrm{CEDH}{ }^{101}$ : el señor Botta solicitó en vano a las autoridades italianas que adoptaran las medidas oportunas para que los concesionarios privados de la playa cercana a donde él residía durante sus vacaciones aplicasen efectivamente la legislación nacional que les obligaba a disponer un acceso a la playa para las personas con discapacidad. En opinión de la desaparecida Comisión Europea de Derechos Humanos, y después del Tribunal Europeo, el derecho social de las personas con discapacidad a la participación en la vida de la comunidad se desprendería más bien del artículo 15 CSER. El factor determinante fue, sin embargo, que «el derecho reivindicado por el señor Botta, a saber, el de poder acceder a la playa y al mar lejos de su residencia habitual durante las vacaciones, afecta a relaciones interpersonales de un contenido tan amplio e indeterminado que no puede acogerse la existencia de una relación directa entre las medidas exigidas al Estado para poner remedio a las omisiones de los balnearios privados y la vida privada del interesado. Por tanto, no resulta aplicable el artículo $8{ }^{102}$. Por lo demás, una minoría de los miembros de la Comisión Europea de Derechos Humanos se había decantado no obstante a favor de una declaración de violación, tras entender que

100 Cf. STEDH Monnat (n. 55), $\$ 31$ s.: «El Convenio no establece en beneficio de los particulares una especie de actio popularis para la interpretación del Convenio ni autoriza por tanto a los individuos a denunciar in abstracto una ley por el solo motivo de que estime que dicha ley infringe el Convenio. Centrándose en las circunstancias del caso de autos, el Tribunal estima que, en la medida en la que el demandante ha decidido denunciar el carácter inoportuno del control de los programas establecido por la Ley federal sobre la radio y la televisión, dicha argumentación debe ser rechazada, en la medida en que el demandante contesta, en abstracto, un régimen jurídico general, pretendidamente contrario al Convenio".

${ }^{101}$ La DTEDH Molka (n. 78), $\$$ lit. C, en donde el demandante, en silla de ruedas, denunciaba la ausencia de acceso a la cabina para votar, no será abordada en esta sede con mayor detalle. En efecto, su demanda fue declarada manifiestamente infundada (si bien el art. $8 \mathrm{CEDH}$ fue considerado aplicable), en la medida en que habría tenido la posibilidad de solicitar ayuda a otros votantes para acceder a dicha cabina. Además, Polonia — cuyo margen de apreciación era grande en razón de los costes generados por la construcción de accesos a los edificios públicos- se prestaba a aprobar su nueva legislación sobre la edificación, previendo el establecimiento de accesos para las personas con discapacidad.

102 STEDH Botta c. Italia, de 24 febrero de 1998, demanda 21439/93, rec. 1998-i, $\$ 28$ $\& 35$. 
las autoridades italianas habían omitido aplicar su propia legislación y que el artículo $8 \mathrm{CEDH}$ cubría el acceso de todos a los lugares públicos o abiertos al público $^{103}$.

En un segundo asunto, el Tribunal debió examinar si «la infracción del Estado checo de suprimir las barreras arquitectónicas que impedían el acceso de las personas con discapacidad a los centros públicos o abiertos al público» en la ciudad en la que tenían su domicilio era constitutiva de una violación de la vida privada de los demandantes. El Tribunal Europeo se interrogó sobre la frontera entre el campo de aplicación de la Carta Social y del Convenio Europeo, precisando que el artículo $8 \mathrm{CEDH}$ sólo cabe aplicarlo «en los casos excepcionales en donde la falta de accesos a los centros públicos o abiertos al público pueda impedir a la demandante vivir su vida de tal manera que el derecho al desarrollo de su personalidad o su derecho a entablar y mantener relaciones con otros seres humanos y con el mundo exterior queden en entredicho». Ahora bien, sobre haber entendido que los demandantes no «han demostrado la relación especial entre el carácter inaccesible de los centros mencionados y las necesidades particulares derivadas de [su] vida privada", y dado el elevado número de establecimientos denunciados, el artículo 8 fue declarado inaplicable ${ }^{104}$. En comparación con la reclamación n. ${ }^{\circ} 13 / 2002$, esas dos sentencias del Tribunal Europeo revelan claramente las diferencias de enfoque que derivan del tipo de mecanismo de control establecido: mientras que el mecanismo de la Carta invita a las organizaciones reclamantes a denunciar situaciones jurídicas o fácticas que no sean conformes a ella, el mecanismo del Convenio sólo puede tener en cuenta situaciones generales en la medida en que de ellas se desprenda una relación particularmente estrecha con la violación alegada por la víctima. Ello no obstante, no cabe excluir que el Tribunal se muestre más liberal en el futuro: en el asunto Smirnova, en efecto, el Tribunal juzgó que la confiscación del pasaporte interior de la demandante, que ésta necesitaba para poder llevar a cabo las tareas más corrientes de la vida cotidiana o para recibir atención médica o encontrar un empleo, constituía, bajo el ángulo de la ausencia de base legal, una violación de su vida privada ${ }^{105}$. Ahora bien, del mismo modo que la ausencia de pasapor-

${ }^{103}$ Comisión Europea de Derechos Humanos, decisión Botta c. Italia, de 15 octubre de 1996, D.R 84-A, pág. 34: véanse, con algunos matices, los votos particulares discrepantes del Sr. Conforti, al que se adhirieron otros cinco miembros, así como el del Sr. L. Loucaides. Cf. SUDRE (n. 76), pág. 118 ss.

${ }_{104}$ DTEDH Jitka Zehnalova y Otto Zehnal (n. 73), título I in fine.

105 STEDH Smirnova c. Rusia, de 24 julio de 2003, demanda 46133/99; 48183/99, rec. 2003-ix, \$95-100. 
te que habría privado a la Señora Smirnova de un acceso «jurídico» a una cantidad de bienes y servicios de la vida cotidiana ha podido ser considerada relevante a la luz del artículo $8 \mathrm{CEDH}$, en nuestra opinión una demanda bien formulada debería estar en condiciones de acreditar que la existencia de barreras arquitectónicas en los edificios públicos o privados, y cuyo acceso resulta necesario a una persona con discapacidad para que ésta pueda entablar relaciones sociales, profesionales o culturales, entra igualmente en el campo de aplicación de dicha disposición.

\section{CONCLUSIÓN}

A favor de un diálogo a menudo imperceptible, las prácticas jurisprudenciales del Tribunal Europeo de Derechos Humanos y del Comité Europeo de Derechos Sociales se retroalimentan y convergen cada vez más. Desde la entrada en vigor, en 1998, del Protocolo adicional a la Carta Social que establece un sistema de reclamaciones colectivas, este fenómeno ha adquirido aún mayor vigor. La armonización que se está operando se desarrolla en diversos niveles: en primer lugar, en el plano de los conceptos, en donde las jurisprudencias incorporan progresivamente la visión moderna y holística de los derechos humanos y «descubren» sus obligaciones plurales. A continuación, en el terreno de los métodos y de la terminología empleados, en donde el Comité Europeo de Derechos Sociales se esfuerza - con éxito- en colmar el retraso jurisprudencial que le separaba del Tribunal Europeo en razón de la actividad contenciosa más precoz de éste. En fin, en cuanto al fondo, se está desarrollando igualmente una evolución discreta que privilegia la lectura conjunta de los dos textos cada vez que ésta resulte posible. De entrada, la armonización material se encuentra sin embargo limitada por la letra a veces divergente de los dos convenios y por las características propias de cada mecanismo de control.

Si el camino que llevaría a la creación de un Tribunal Social de Derechos Humanos o hacia la instauración de una Sala Social del Tribunal Europeo ha quedado temporalmente obstruido, nada se opone a una intensificación tanto cuantitativa como cualitativa (y, por ende, más audaz si cabe) de las interacciones entre las dos jurisprudencias y los dos instrumentos.

Finalmente, en lo que atañe a la justiciabilidad individual de los derechos sociales consignados en la Carta (revisada), la misma es (o debería ser), desde ya, puesta en práctica a través de la cooperación vertical que prescribe el Comité Europeo de Derechos Sociales a las instancias jurisdiccionales nacionales. En su decisión n. ${ }^{\circ}$ 12/2002, y con cierta extrapolación, el Comité había considerado en 
efecto que correspondía a las jurisdicciones nacionales aplicar la Carta Social en los litigios individuales sustanciados ante ellas, y ello a la luz de los principios interpretativos sentados por el Comité. Éste, por lo demás, se reservaba «la posibilidad de controlar que tal habría sido el caso, a través del procedimiento de informes y, en su caso, del procedimiento de reclamaciones colectivas» ${ }^{106}$.

\section{Title}

«The Harmonisation of Jurisprudential Approaches of the European Court of Human Rights and the European Committee of Social Rights: a discreet evolution».

\section{Palabras clave}

Tribunal Europeo de Derechos Humanos - Comité Europeo de Derechos Sociales - armonización - convergencia de prácticas jurisprudenciales - simetría - obligaciones tripartitas - interdependencia de los derechos humanos - fertilización cruzada de jurisprudencias - reclamaciones colectivas - justiciabilidad

\section{Key words}

European Court of Human Rights - European Committee of Social Rights - harmonisation - convergence of practices - symmetry - tripartite obligations - interdependence of Human Rights - cross-fertilisation of case-law - collective complaints - justiciability

\section{Summary}

I. Prolegomena: What Harmonisation? II. The Fundamental Civil and Social Rights: theoretical convergences: 1 . The Interdependence. 2. The Multi-layered Duties. III. The Court and the Committee: practical convergences: 1. An Obligational Symmetry? 2. Intermingling and Cross-References. 3. The Limits to Autonomous Harmonisation. IV. Conclusion

\section{Resumen}

En las últimas décadas está teniendo lugar un discreto, aunque continuo, proceso de convergencias y fertilización cruzada o entrecruzamiento entre, de un lado, los derechos fundamentales conocidos como

106 DCEDS Confederación de empresas suecas (CES) c. Suecia, de 15 mayo de 2003, reclamación n. ${ }^{\circ}$ 12/2002 (fondo), $\$ 42 \mathrm{~s}$. 
civiles y políticos y, de otro lado, los esenciales si bien frecuentemente subestimados derechos humanos conocidos como derechos económicos, sociales y culturales.

Desde un punto de vista teórico, los autores admiten ampliamente en la actualidad que ambos "grupos» de derechos humanos son indivisibles, interdependientes e interrelacionados, en el sentido de que ninguna categoría puede en puridad cumplir con sus tareas protectoras si la otra está siendo sistemáticamente violada y/o sacrificada en el altar de un utópico bien común. Además, cada derecho humano genera per se múltiples «oleadas de deberes» que deben ser abordadas por los Estados y por sus agentes. Desde una perspectiva académica, esas oleadas se reconducen tradicionalmente a tres tipos de obligaciones: respetar, proteger y cumplir cada derecho humano.

La práctica y la jurisprudencia que se viene desarrollando por el Tribunal Europeo de Derechos Humanos y por el Comité Europeo de Derechos Sociales ponen de manifiesto lo que en verdad se esconde detrás de esos conceptos teóricos, ya sea con relación a los tipos de deberes que pesan sobre los Estados y cuya protección viene encomendada a cada órgano internacional, ya sea con respecto a los fuertes vínculos que existen y seguirán existiendo entre cada "grupo» de derechos humanos. Por añadidura, el Tribunal Europeo de Derechos Humanos y el Comité Europeo de Derechos Sociales se están remitiendo crecientemente cada uno a la jurisprudencia del otro, especialmente desde el momento en que al Comité Europeo se le atribuyó la competencia de examinar reclamaciones colectivas y, con ella, la de ejercer poderes cuasijudiciales. Aunque limitada por diversos factores, la armonización de métodos, vocabulario, enfoques e interpretaciones se va abriendo camino y, con el tiempo, avanzando hacia la práctica realización de una plena igualdad de trato entre los derechos humanos civiles y sociales.

\begin{abstract}
In the past few decades a discreet, albeit continuous process of convergencies and cross-fertilisation has been taking place between, on the one hand, those fundamental human rights known as civil and political and, on the other hand, those essential, yet oftentimes underestimated human rights named economic, social and cultural rights.

From a theoretical standpoint, authors now widely admit that both "groups» of human rights are indivisible, interdependent and interrelated, in the sense that no category can properly accomplish its protective tasks where the other is being systematically violated and/or sacrificed on the altar of some utopian common good. Furthermore,
\end{abstract}


each human right engenders per se multiple "waves of duties» to be met by the states and their agents. Academically, these waves are traditionally broken down to three types of obligations: to respect, to protect and to fulfil each human right.

The practise and case-law which are being developped by the European Court of Human Rights and the European Committee of Social Rights bear witness to the truth behind these theoretical concepts, be it with respect to the kinds of duties with the protection of which each international body is charging the state parties or be it regarding the strong linkages that exist and still prosper between each "group» of human rights. Moreover, the Court and the Committee increasingly refer to each other's case law, especially since the day that the Committee was doted with the power to examine collective complaints and thus exert quasi-judicial powers. Although being limited by several factors, the harmonisation of methods, vocabulary, approaches and interpretations is making its way and, eventually, pointing toward the practical realisation of a full-fledged equality of treatment between civil and social human rights. 